Scientia Marina 75(1)

March 2011, 17-40, Barcelona (Spain)

ISSN: 0214-8358

doi: $10.3989 / \mathrm{scsimar} .2011 .75 \mathrm{n} 1017$

\title{
Lithistid sponges from submarine caves in the Mediterranean: taxonomy and affinities
}

\author{
ANDRZEJ PISERA ${ }^{1}$ and JEAN VACELET ${ }^{2}$ \\ ${ }^{1}$ Institute of Paleobiology, Polish Academy of Sciences, ul. Twarda 51/55, 02-818 Warszawa, Poland. \\ E-mail: apis@twarda.pan.pl \\ ${ }^{2}$ Centre d'Océanologie de Marseille, Aix-Marseille Université, CNRS UMR 6540 DIMAR, Station Marine d'Endoume, \\ Rue de la Batterie des Lions, 13007 Marseille, France.
}

\begin{abstract}
SUMMARY: Several lithistid sponges are described from Mediterranean caves occurring in the northwestern and Adriatic basins. In the Corallistidae, Neoschrammeniella bowerbanki and Neophrissospongia nolitangere are recorded for the first time from the Mediterranean, whereas Neophrissospongia radjae n. sp. and Neophrissospongia endoumensis $\mathrm{n}$. $\mathrm{sp}$. are described as new. In the Theonellidae, the common sponge previously identified as Discodermia polydiscus is described as Discodermia polymorpha $\mathrm{n}$. sp. Fossil specimens from the 3PP cave are tentatively attributed to Neoschrammeniella bower-
\end{abstract} banki. The distribution and affinities of this lithistid fauna are discussed.

Keywords: Porifera, lithistids, new species, Mediterranean Sea, submarine caves, biogeographic affinities, fossilized sponges.

RESUMEN: Esponjas lithistidas de cuevas submarinas en el Mediterráneo: su taxonomía y Relaciones. - Se describen varias esponjas lithistidas procedentes de cuevas del noroeste del mar Mediterráneo y de las cuencas del mar Adriático. Dentro de las esponjas incluidas en la familia Corallistidae, Neoschrammeniella bowerbanki y Neophrissospongia nolitangere, se registran por primera vez en el Mediterráneo y Neophrissospongia radjae n. sp. y Neophrissospongia endoumensis n. sp. se describen como nuevas especies. Dentro de la Familia Theonellidae, la esponja común, que hasta la fecha se había identificado como Discodermia polydiscus se describe como Discodermia polymorpha n. sp. Ejemplares fósiles de la cueva de los 3PP se asignan provisionalmente a Neoschrammeniella bowerbanki. Se discute la distribución y afinidades de la fauna de las lithistidas.

Palabras clave: Porifera, lithistidas, nuevas especies, Mediterráneo, cuevas submarinas, afinidades biogeográficas, esponjas fósiles.

\section{INTRODUCTION}

Submarine shallow water caves in the Mediterranean represent a very special, fragmented habitat with conditions analogous to bathyal. One of the particularities of these caves is a common occurrence of lithistid sponges. Lithistid sponges are rare in the Mediterranean Sea and only 9 species of 9 genera have been reported so far (see detailed review in Manconi et al., 2006; Manconi and Serusi, 2008, and references herein). Those cited from submarine caves are even less common and are poorly studied. Only six lithistid species of six genera were reported from submarine caves: these are Discodermia polydiscus (Bowerbank,
1869) (Theonellidae Lendenfeld, 1903) and Corallistes masoni (Bowerbank, 1869) (Corallistidae Sollas, 1888) from the caves around Marseille (Pouliquen, 1969a, b, 1972), Gastrophanella phoeniciensis Perez, Vacelet, Bitar and Zibrowius, 2004 (Siphonidiidae Lendenfeld, 1903) and Microscleroderma lamina Perez, Vacelet, Bitar and Zibrowius, 2004 (Scleritodermidae Sollas, 1888) from a Lebanese cave (Perez et al., 2004), Aciculites mediterranea Manconi, Serusi and Pisera, 2006 (Scleritodermidae Sollas, 1888) from a northern Sardinian cave (Manconi et al., 2006), and Neophrissospongia nana Manconi and Serusi, 2008 (Corallistidae Sollas, 1888) from a western Sardinian cave. The species Discodermia polydiscus and Coral- 
listes masoni were also recorded from the deep sea in the bathyal zone (Vacelet, 1969; Magnino et al., 1999, respectively). The most commonly cited in the literature is the theonellid Discodermia polydiscus, which occurs in numerous caves (sometimes in large populations) along the Spanish and French coast, as well as on the Sardinian coast (Dr. R. Manconi, pers. inf. 2006) and the Dalmatian coast (Croatia) (Dr. Tatjana BakranPetricioli, pers. inf. 2006). Two or even three species of lithistids may occur in one cave, but usually only one species is observed.

In this paper we examine the lithistids collected over years in several caves from the western Mediterranean, along the French coast near Marseille and on the Spanish coast of the Medes Islands, and in several caves along the Dalmatian coast of Croatia in the Adriatic.

\section{MATERIALS AND METHODS}

Most of the studied sponges were collected over several years of investigations from the submarine caves in the western Mediterranean (Fig. 1). Specimens of Discodermia from the Dalmatian caves (Fig. 1) were collected and donated for research by Dr. Tatjana Bakran-Petricioli (University of Zagreb, Croatia), and one specimen of Neophrissospongia was collected by Mr Tonci Radja (Speleological Society "Spiljar", Croatia).

Western Mediterranean caves: 3PP cave, near La

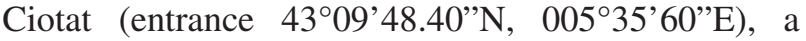
120-m-long tunnel, with a descending profile, depth 15 $\mathrm{m}$ (entrance) to $24 \mathrm{~m}$ (inner part) trapping a cold water masse (Vacelet et al., 1994).

Endoume cave, Marseille (entrance $43^{\circ} 16^{\prime} 47.3^{\prime \prime} \mathrm{N}$, $\left.005^{\circ} 21^{\prime} 00.3^{\prime \prime} \mathrm{E}\right)$, a small semi-obscure cave with sev- eral openings, rather exposed, $10 \mathrm{~m}$ long, $5 \mathrm{~m}$ deep (Pouliquen, 1972).

Trémies cave, near Cassis (entrance $43^{\circ} 12^{\prime} 22^{\prime}$ N $\left.005^{\circ} 31^{\prime} 008^{\prime \prime} \mathrm{E}\right)$, a large, dark cave, depth $19 \mathrm{~m}$ (entrance) to $3 \mathrm{~m}$ (inner part) (Pouliquen, 1972).

Gaméou cave, near La Ciotat (entrance $\left.43^{\circ} 09^{\prime} 53.40^{\prime \prime} \mathrm{N}, 005^{\circ} 35^{\prime} 55.42^{\prime \prime} \mathrm{E}\right)$, a large dark cave, depth $15 \mathrm{~m}$ (entrance) to $0 \mathrm{~m}$ (inner part).

Cap Morgiou cave, near Marseille (entrance $43^{\circ} 12^{\prime} 07.07^{\prime} \mathrm{N}, 005^{\circ} 27^{\prime} 09.77^{\prime \prime} \mathrm{E}$ ), a vertical pit with an opening at its lower part, depth 15-32 m (Pouliquen, 1972).

Medes Islands, Spain (4202'35'N, 003 $\left.{ }^{\circ} 13^{\prime} 36^{\prime \prime} \mathrm{E}\right)$, dolphin cave, a dark cave $50 \mathrm{~m}$ long, depth $0 \mathrm{~m}$ (inner part) to $12 \mathrm{~m}$ (entrance) (Zabala et al., 1989).

Figuier cave, near Marseille (entrance $\left.43^{\circ} 12^{\prime} 19.1^{\prime \prime} \mathrm{N}, 005^{\circ} 26^{\prime} 48.43^{\prime \prime} \mathrm{E}\right)$, a dark cave with several openings, depth 10-20 m (Pouliquen, 1972).

Jarre III cave, near Marseille (entrance 43 ${ }^{\circ} 11^{\prime} 46^{\prime}$ N, $005^{\circ} 21^{\prime} 55^{\prime} \mathrm{E}$ ), a ca. $130 \mathrm{~m}$ long, dark tunnel, depth $15-$ $17 \mathrm{~m}$.

Dalmatian caves (Croatia) (Bakran-Petricioli and Kružić, 2002):

Cave no. 1, Lastovo, Ubli, Pasadur, with descending profile $\left(42^{\circ} 45^{\prime} 49.6^{\prime} \mathrm{N}, 16^{\circ} 49^{\prime} 18.1^{\prime \prime} \mathrm{E}\right)$.

Cave no. 2, pit near Island Balkun, Šolta, with descending profile ( $\left.43^{\circ} 23^{\prime} 41.0^{\prime \prime} \mathrm{N}, 16^{\circ} 12^{\prime} 07.3^{\prime \prime} \mathrm{E}\right)$.

Cave no. 3, pit cave in Kravljačica cove, Kornat

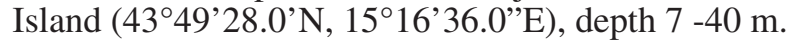

Cave no. 4, Y cave, Brbinjšćica cove, Dugi Otok

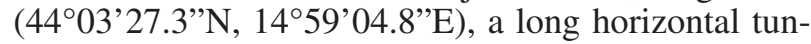
nel, depth 3-4 m.

Cave no 5, Dalmatian cave (Croatia), Korkula Island $\left(42^{\circ} 57^{\prime} 16.26^{\prime \prime} \mathrm{N}, 17^{\circ} 07^{\prime} 52.21^{\prime \prime} \mathrm{E}\right.$ for the town of

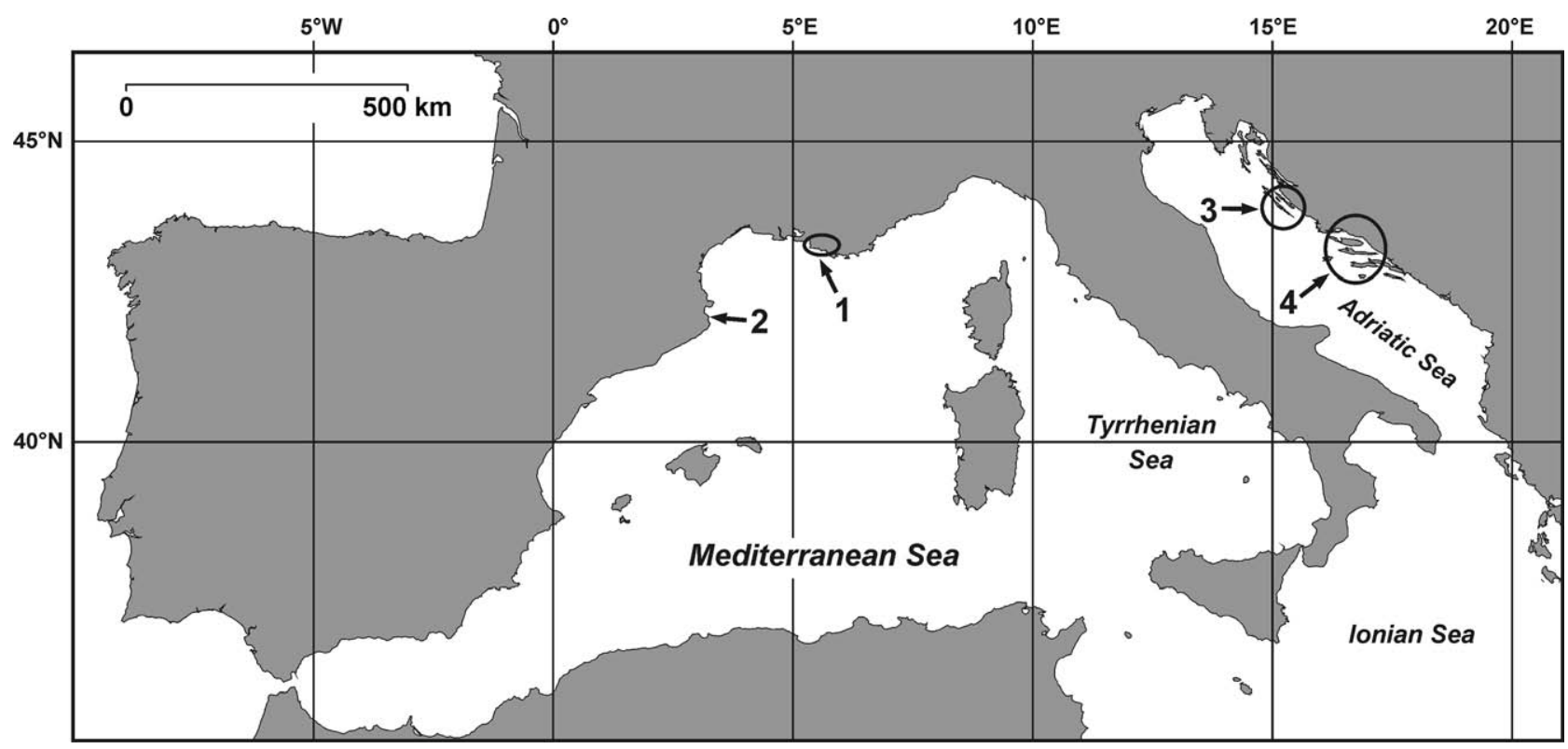

FIG. 1. - Map of the Mediterranean Sea with location of lithistid-inhabited caves. Western Mediterranean: 1, Endoume, 3PP, Gameau, Trémies, Jarre III, Cap Morgiou; 2, Medes Islands. Dalmatian coast: 3, Dugi Otok Island, Kornat Island; 4, Balkun Island, Korkula Island, Lastovo Island. 
TABLE 1. - Spicule size $(\mu \mathrm{m})$ of the investigated corallistid species

\begin{tabular}{|c|c|c|c|c|c|}
\hline Species & Dichotriaenes & Desmas & Microstyles & Spirasters I & Spirasters II \\
\hline Neophrissospongia radjae & $\begin{array}{l}\text { Cladome tuberculated } \\
208-287 \\
\text { Rhabdome } \\
355-639\end{array}$ & $280-387$ & $88.5-128 \times 2.1-2.73$ & $9.55-15.5 \times 8.35-12$ & absent \\
\hline Neophrissospongia nolitangere & $\begin{array}{l}\text { Cladome tuberculated } \\
184-313 \\
\text { Rhabdome } \\
297-629\end{array}$ & $289-382$ & $74-137 \times 1.40-2.1$ & $8.36-15.4 \times 6.14-12.9$ & absent \\
\hline Neophrissospongia endoumensis & $\begin{array}{l}\text { Cladome spinose } \\
248-283 \\
\text { Rhabdome } \\
531-615\end{array}$ & $318-490$ & $68.8-123.0 \times 1.7-3.16$ & $12.7-20.1 \times 11.3-16.6$ & absent \\
\hline Neoschrammeniella bowerbanki & $\begin{array}{l}\text { Cladome smooth } \\
176-323 \\
\text { Rhabdome } \\
223-513(748)\end{array}$ & $290-402$ & absent & $\begin{array}{l}\text { 17.2-24x 7.06-11.1 } \\
\text { (short arms) }\end{array}$ & $\begin{array}{c}26.2-39.2 \mathrm{x} \\
18.5-23.99 \\
\text { (long arms) }\end{array}$ \\
\hline
\end{tabular}

Korkula, exact position of the cave unknown).

Dredging $360 \mathrm{~m}$ depth in the Cerigotto Canal, Aegean Sea between Crete and the Peloponnese, $35^{\circ} 45^{\prime} \mathrm{N}, 23^{\circ} 25^{\prime} \mathrm{E}$, depth $360 \mathrm{~m}, 31 / 05 / 1964$.

For the study of spicules, the sponge tissue was digested in hot $\mathrm{HNO}_{3}$, then acid was removed by washing several times with distilled water and finally with propanol. A suspension of loose spicules was dropped on the stub surface, dried and covered with platinum or gold-palladium for observations under a Phillips XL 20 (Warszawa) and a Hitachi S570 (Marseille) scanning electron microscopes. Histological preparations including both living tissue and skeleton were made by embedding in epoxy resin (C) Araldite sponge fragments stained with acid fuchsin. The inclusions were then cut with a low-speed saw using a diamond wafering blade. The sections were wet-ground on abrasive discs, and later mounted on glass slides for transmitted light observations.

The investigated material is housed in the Institute of Paleobiology under ZPAL Pf.21 and in MNHN Paris under MNHN-JV-119 to 129. List of acronyms used: BMNH - Natural History Museum, London, Great Britain; MNHN - Muséum national d'Histoire naturelle, Paris, France; MZUS - Musée Zoologique de Strasbourg, Strasbourg, France, ZMA - Zoölogische Museum, Amsterdam, the Netherlands; ZPAL Institute of Paleobiology, Polish Academy of Sciences, Warsaw, Poland.

\section{SYSTEMATICS}

Class Demospongiae, Sollas, i 875

Family CoRALLISTIDAE Sollas, 1888

Diagnosis (from Pisera and Lévi, 2002a). Polymorphic; massive, ear, vase, cup-shaped; choanosomal desmas as dicranoclones, ectosomal spicules as dichotriaenes and sometimes additionally simple triaenes; microscleres can be spirasters (often two types), streptasters/amphiasters, microxeas, microstyles and microstrongyles.
Genus Neoschrammeniella Pisera and Lévi, 2002a

Type species. Iouea moreti Lévi and Lévi, 1988.

Diagnosis [emended after Pisera and Lévi (2002a), Schlacher et al. (2005), Kelly (2007)]. Polymorphic Corallistidae (cylindrical to cup/vase shaped) with smooth ectosomal dichotriaenes; microscleres as two to three types of acanthose spirasters (short blunt rays and different size classes of long or short pointed rays) as microscleres. Choanosomal anisoxeas and larger fringing diactine megascleres may be present in some species.

Remarks. So far this genus was known only from the SW Pacific region, and this is the first report outside that region. However, the species Corallistes bowerbanki (here attributed to Neoschrammeniella) was earlier known from the Atlantic (see Sollas, 1888).

Neoschrammeniella bowerbanki (Johnson, 1863) (Figs. 2K-L, 4-5, Table 1)

Dactylocalyx bowerbanki Johnson, 1863: 257; Bowerbank, 1869: 94, Pl. 6, Figs. 5-8.

Corallistes bowerbanki; Carter, 1876: 460; Sollas, 1888: 308.

Corallistes masoni (Bowerbank, 1869); Pouliquen, 1969a: 42, Pl. 8, Fig. 2; Pouliquen, 1969b: 1325; Pouliquen, 1972: 749, Pl. 9 , Fig. 2 .

Non Corallistes bowerbanki; Topsent, 1892 (=Neophrissospongia nolitangere).

Material. 3PP cave, several specimens ( $\mathrm{N}^{\circ} 12,14 / 03 / 1991$, MNHNDJV-124; N 13, 17/09/1991, MNHN-DJV-125).

Other material examined. Corallistes masoni (Bowerbank), holotype BMNH 77.5.21.7. Corallistes bowerbanki (Johnson), holotype BMNH 69.11.60.1 (PZS 1862).

Diagnosis. Cup-shaped to contorted lamellate masses with thick walls; ectosomal dichotriaenes smooth; choanosomal desmas with high irregular tubercles which may be sculptured with low tubercles; microscleres are two types of spirasters: one with short and thick arms, the second with long thin and pointed arms. 


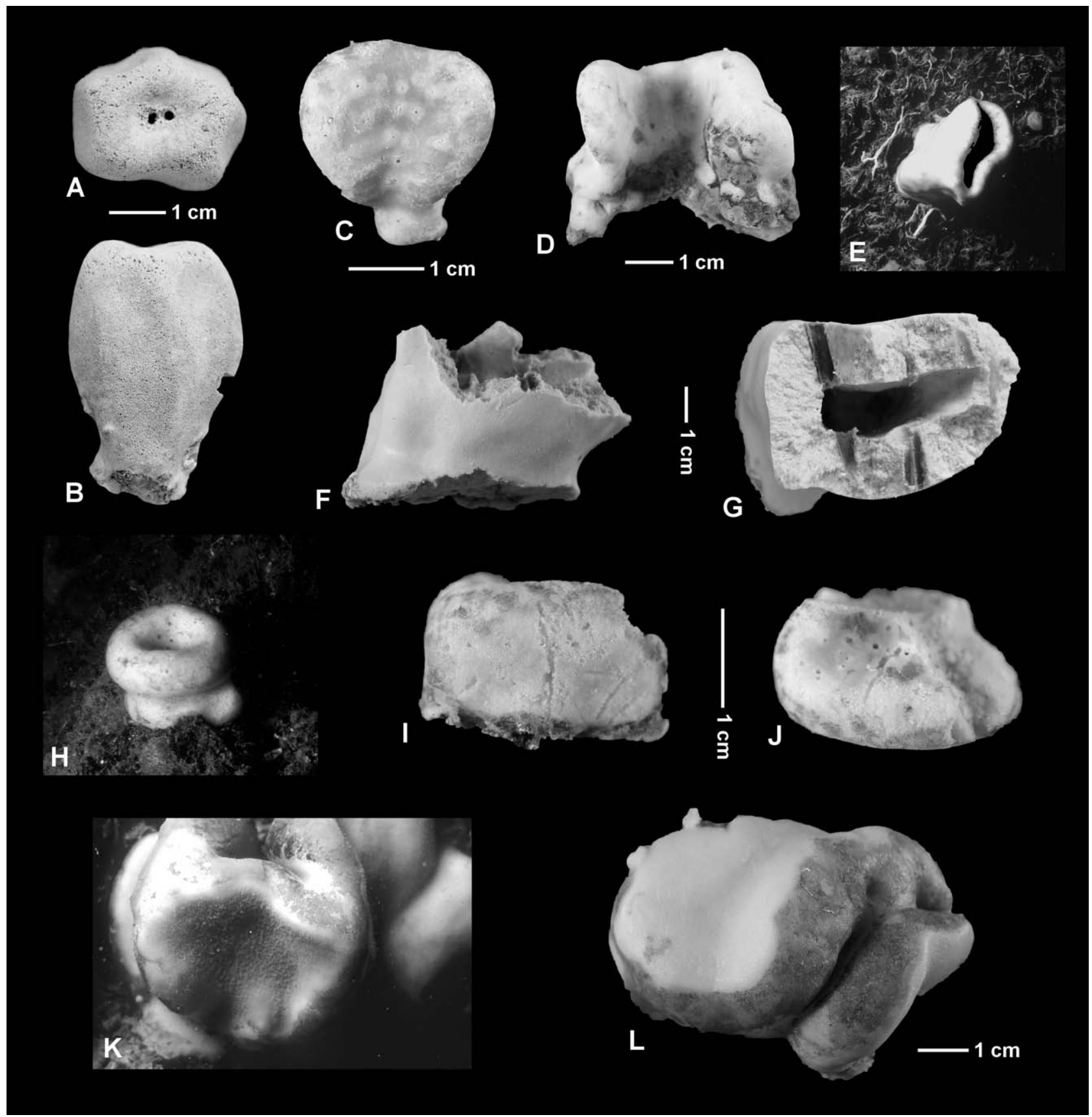

FIG. 2. - Morphology of the corallistid lithistids. A, B, Neophrissospongia radjae n. sp., holotype, MNHN-DJV-119, top and side views; C-G, Neophrissospongia nolitangere (Schmidt, 1870), C specimen MNHN-DJV-122, Gameau, 25/09/1992], D, specimen MNHN-DJV-123 (14, 31/03/98); E-G, specimen MNHN-DJV-121 (16/09/1991), 3PP (E in situ, all 3PP cave); H-J, Neophrissospongia endoumensis n. sp., holotype, specimen MNHN-DJV-120 (26/02/1980); H, in situ, Endoume cave; K, L, Neoschrammeniella bowerbanki (Johnson, 1863), specimen MNHN-DJV-124 (14/03/1991), K, in situ, 3PP cave.

Description. Relatively large massive sponges, $8 \mathrm{x}$ $6 \times 6 \mathrm{~cm}$, in shape of irregular cup to contorted lamellae $10-15 \mathrm{~mm}$ thick. Colour clear brown to cream in life and in alcohol. Surface smooth to the naked eye, but under the microscope one side (the internal one) with numerous thin oxeas protruding from the choanosome, giving a hairy appearance to its surface. The sponge was attached directly by the lower part to the hard substrate.
Ectosome with dichotriaenes and densely packed microscleres of spiraster type. Outer sponge surface smooth with densely packed ectosomal dichotriaenes visible on the surface. Inner surface hispid with numerous small bunches of tiny oxeas protruding from the choanosome.

Choanosomal desmas are dicranoclones forming net-like meshwork on both sides, with oval to angular meshes. Dicranoclones are approximately 290-402 um 


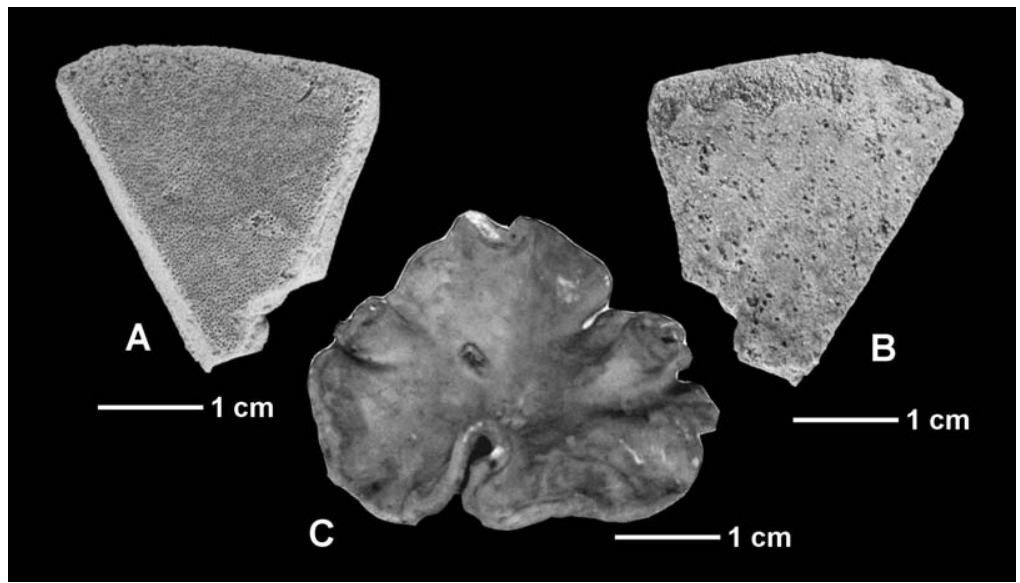

FIG. 3. - A-B, Corallistes masoni (Bowerbank, 1869), fragment of the holotype BMNH 77.5.21.7.; A, Inner surface view, B, Outer surface view. C, Corallistes bowerbanki (Johnson, 1863), holotype BMNH 69.11.60.1 PZS 1862, upper side view.

in size. They are rather irregular, highly arched and covered with numerous high and irregular tubercles which are in turn divided into several smaller irregular lobes/tubercles.
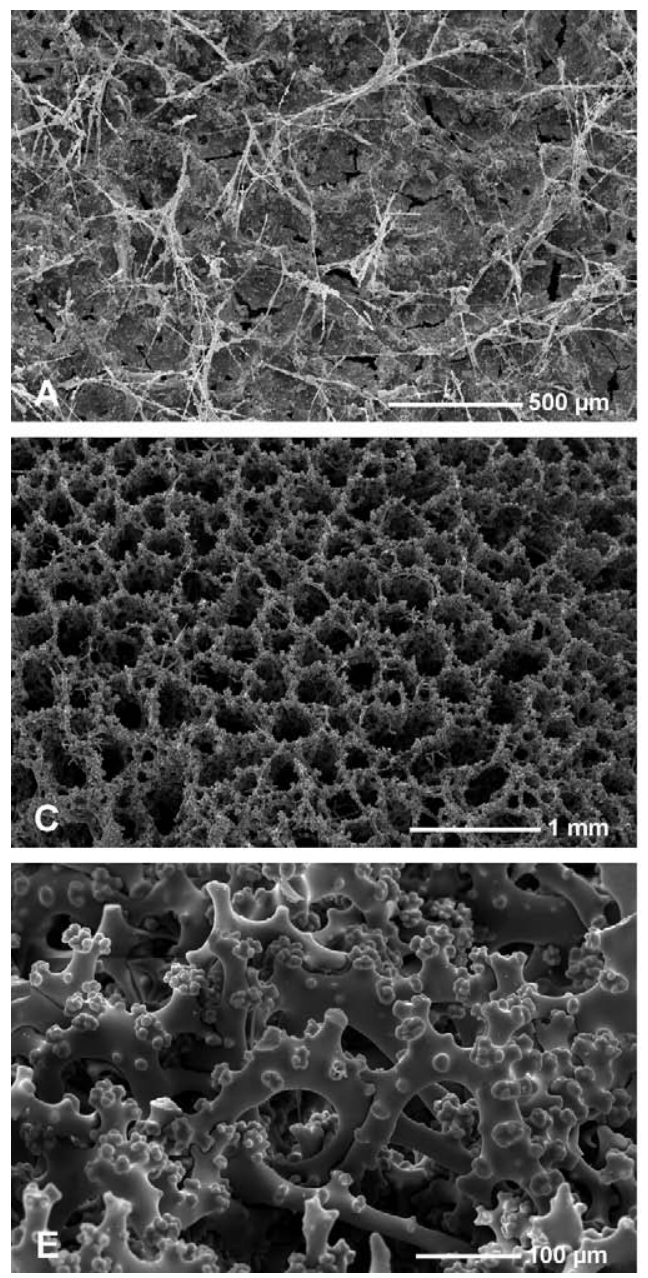

FIG. 4. - Neoschrammeniella bowerbanki (Johnson, 1863), 3PP cave specimen MNHN-DJV-124 (14/03/1991). A, Upper natural surface view, note numerous thin oxeas protruding from the choanosome; B, Lower natural surface view, with smooth ectosomal dichotriaenes; C, Surface of the choanosomal skeleton, inhalant surface; D, Ectosomal dichotriaenes in situ on inhalant surface; E, Oblique view of the dicranoclone desmas of the choanosomal skeleton; F, Details of articulation and sculpture of dicranoclone desmas. 


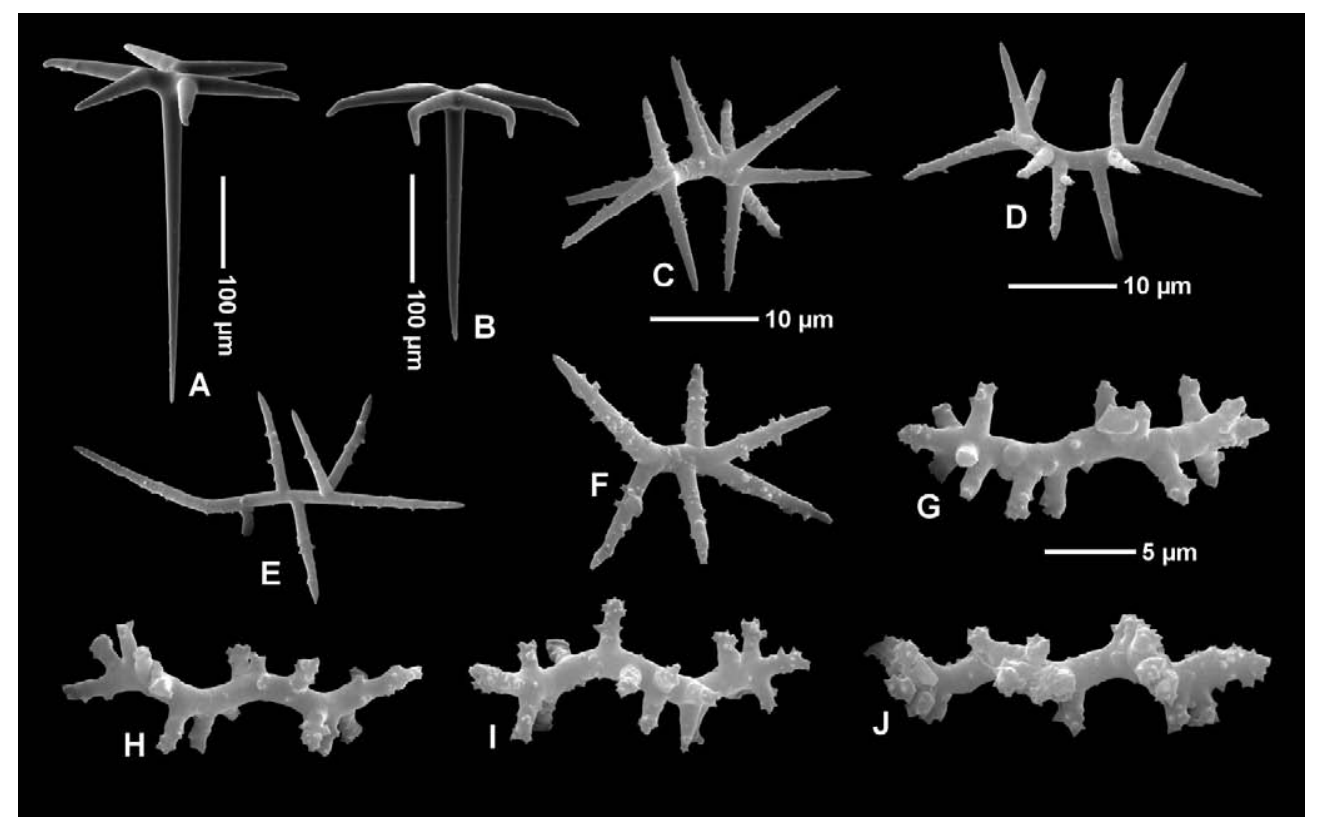

FIG. 5. - Neoschrammeniella bowerbanki (Johnson, 1863), 3PP specimen MNHN-DJV-124 (14/03/1991). A, B, Ectosomal dichotriaenes with smooth cladome; C-F, Spinose spirasters type II with long slender arms; G-J, Spinose spirasters type I with short thick arms.

$\mu \mathrm{m}$. Oxeas straight, very thin, 340-820 x 1.5-2.5 $\mu \mathrm{m}$.

Microscleres are two types of spirasters; type I has short and thick rays with numerous massive, often bifid spines, and measures 17-24 $\mu \mathrm{m} \times$ 7.06 -11.1 $\mu \mathrm{m}$; type II has long thin and pointed arms which are sparsely covered with tiny spines, and measures 26.2-39.2 x 18.5-23.9 $\mu \mathrm{m}$.

Remarks. No formal diagnosis was ever given for $N$. bowerbanki, so we present it here. This species was originally attributed by Johnson (1863) and Bowerbank (1869) to the genus Dactylocalyx (hexactinellid sponge), and by Sollas (1888) to the genus Corallistes Schmidt, 1879. Based on skeletal characters we decided to transfer it to the genus Neoschrammeniella Pisera and Lévi, 2002a. The main difference between Corallistes and Neoschrammeniella is in the microscleres: Corallistes has two types of massive spirasters with pointed arms, while Neoschrammeniella has two types of long spirasters, one with pointed and one with blunt arms (Pisera and Lévi, 2002a).

$N$. bowerbanki has usually been reported from the Mediterranean under the name C. masoni (Bowerbank). We consider this determination clearly erroneous based on comparison of the studied cave material and the examination of type material of both $C$. bowerbanki (Figs 3C, 6-7) and C. masoni (Figs 8-9). We illustrate here, for comparison, for the first time in SEM, spiculation of the holotypes of these two species. The investigated Mediterranean material is thick walled while the type of $C$. masoni has much thinner walls; C. masoni has only one type of long spirasters with long and thin arms, while the type of $C$. bowerbanki and our specimens have two types of spirasters of different morphology (see description). This difference in microscleres was already observed by Carter (1873). Based on these observations the identity of the described specimens from Mediterranean caves with the species $C$. bowerbanki, and not with $C$. masoni, is beyond any doubt. Topsent (1892) described and illustrated under the name $C$. bowerbanki a species which has dichotriaenes with tuberculated cladome, similar to that in Neophrissospongia nolitangere, as well as abundant "linear" microxeas, which are most probably spinose microstyles recognized also in that species.

Occurrence. 3PP cave (this study), Figuier and Cap Morgiou caves (Pouliquen, 1972). In the 3PP cave, the sponge was attached to vertical walls, approximately $85 \mathrm{~m}$ from cave opening, 20-22 m depth, in a water mass with a nearly constant temperature, ca 13 to $15^{\circ} \mathrm{C}$.

Distribution. Eastern Atlantic Ocean, Mediterranean Sea.

\section{Genus Neophrissospongia Pisera and Lévi, 2002a} 1870

Type species. Corallistes nolitangere Schmidt,

Emended diagnosis (after Pisera and Lévi, 2002a). Irregular cup-shaped to contorted lamellate masses, ear-shaped or massive clavate growth forms. Ectosomal spicules are dichotriaenes bearing on the upper cladome surface strong spines and/or tubercles; choanosomal desmas are dicranoclones; microscleres are massive streptasters/amphiasters and spinose microtylostyles. 

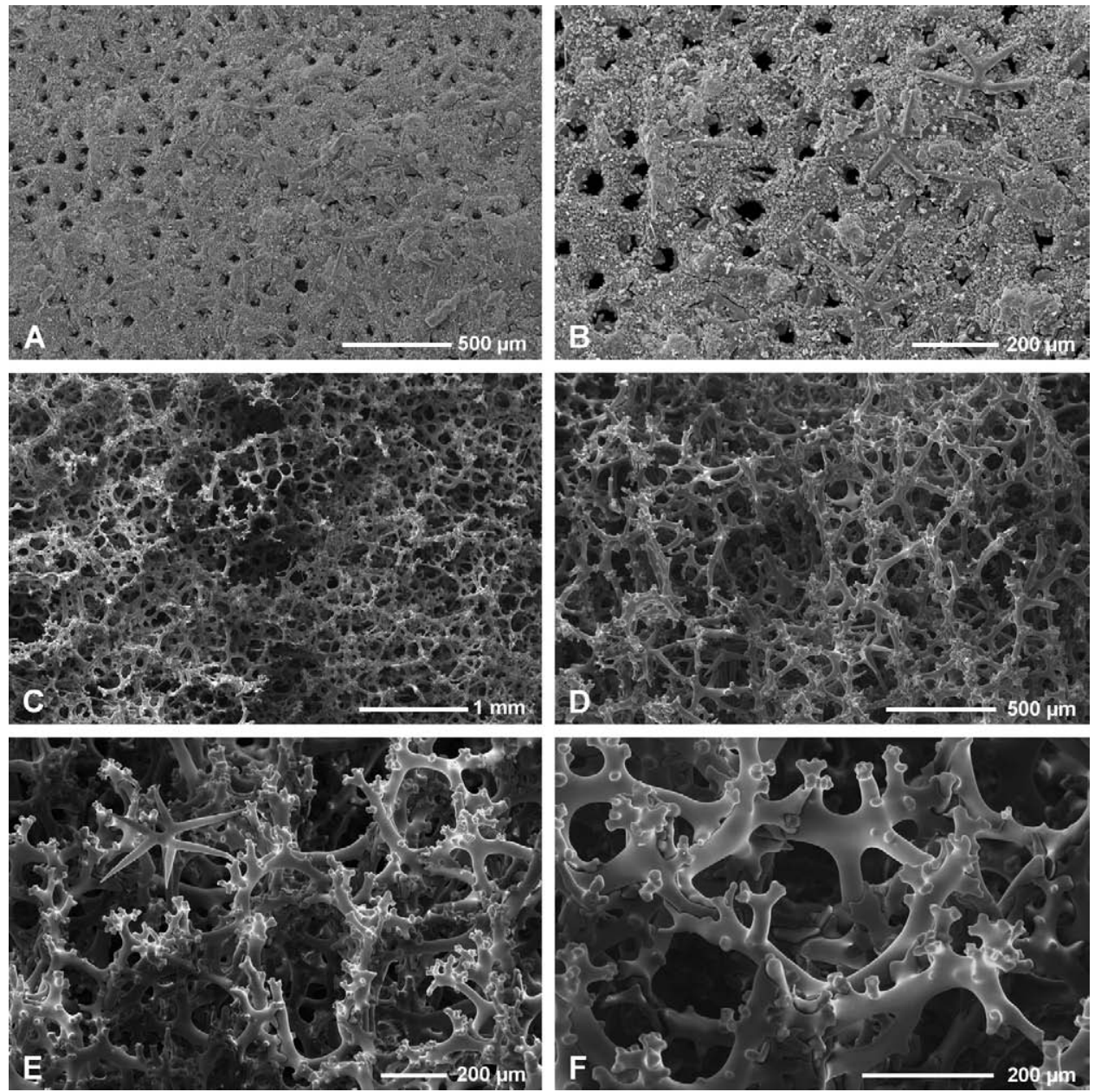

FIG. 6. - Neoschrammeniella bowerbanki (Johnson, 1863), holotype BMNH 69.11.60.1 PZS 1862. A, B, Lower natural surface showing numerous ostia and smooth ectosomal dichotriaenes (B); C, D, Upper surface view of the choanosomal skeleton of dicranoclone desmas; E, $\mathrm{F}$, Details of dicranoclone desma sculpture and articulation.

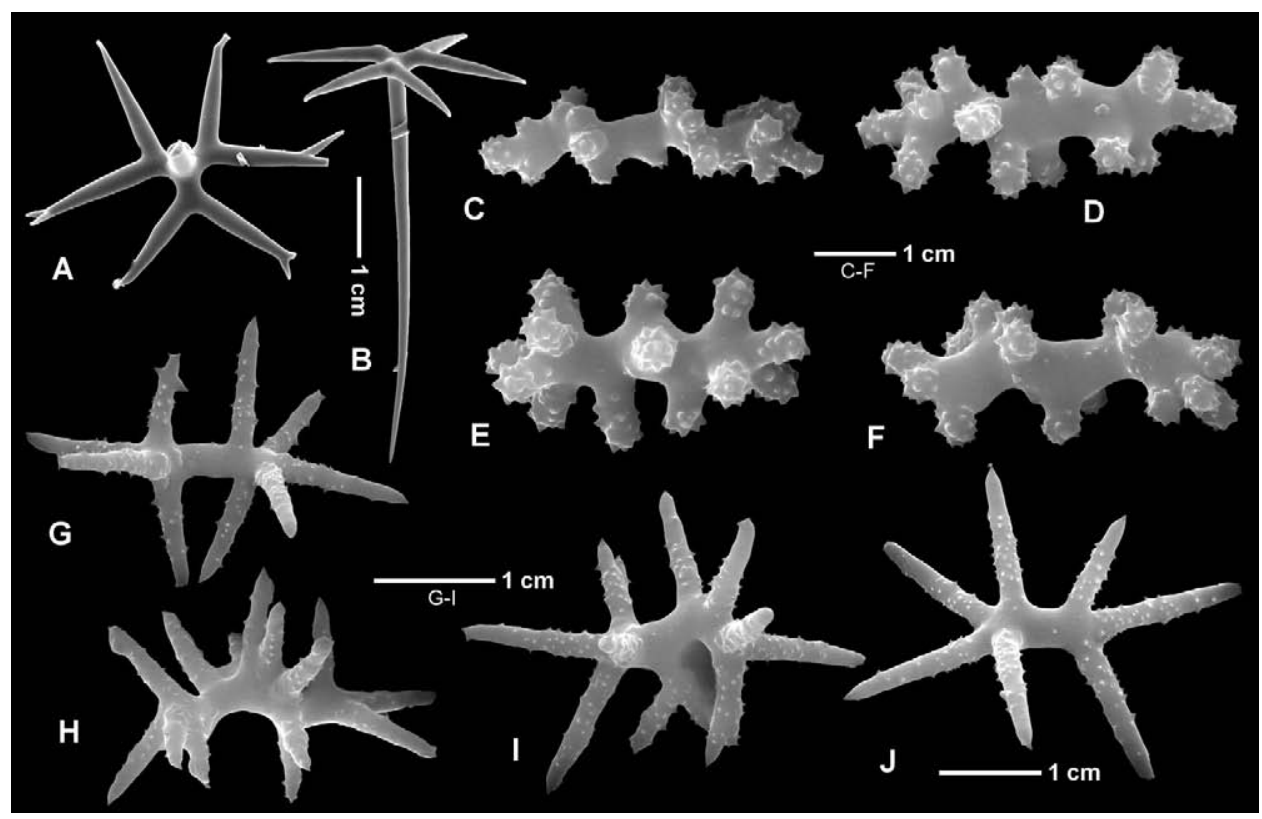

FIG. 7. - Neoschrammeniella bowerbanki (Johnson, 1863), holotype BMNH 69.11.60.1 PZS 1862. A, B, Ectosomal dichotriaenes; C-F, Spirasters type I; G-J, Spirasters type II. 

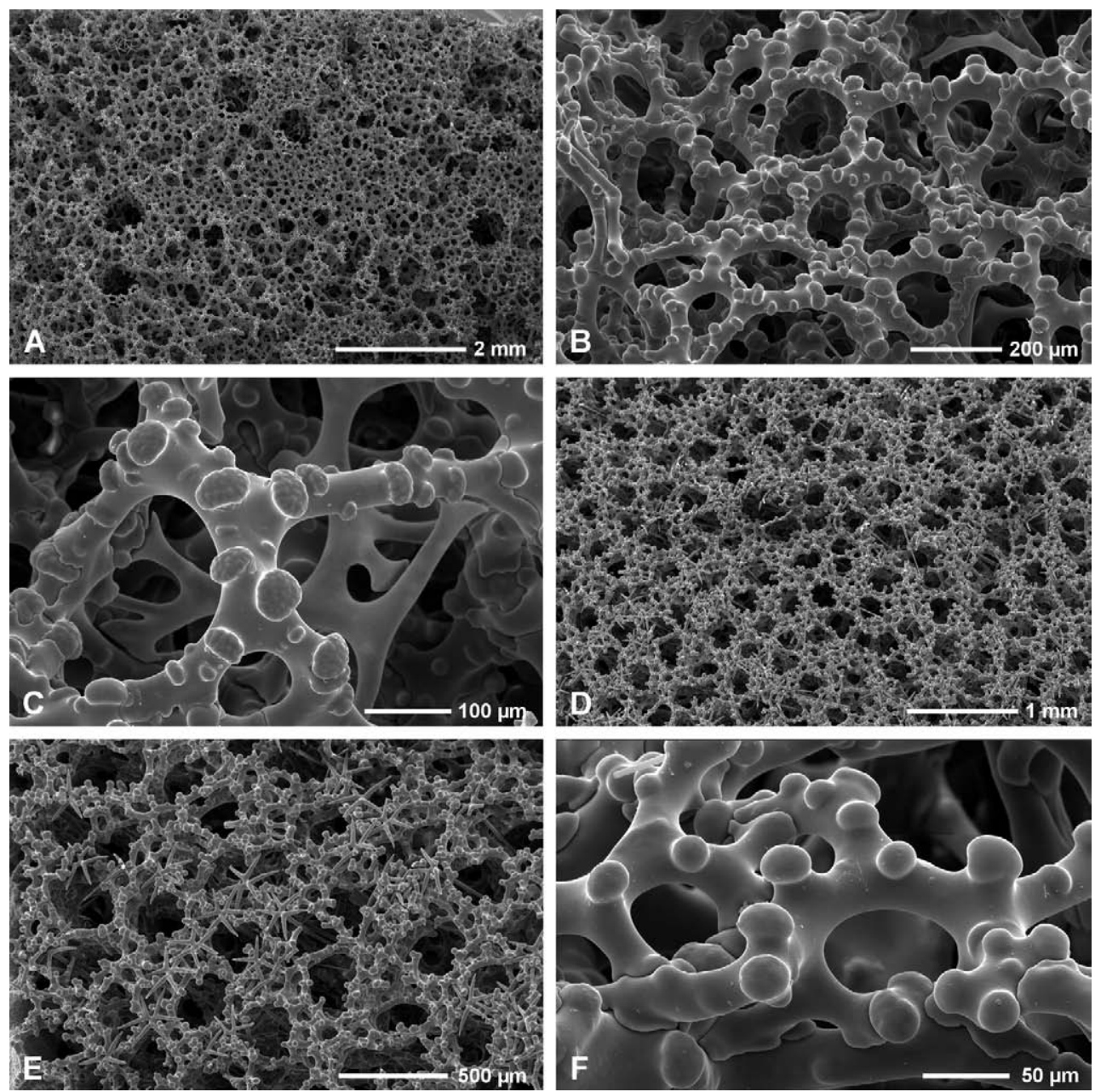

FIG. 8. - Corallistes masoni (Bowerbank, 1869), holotype BMNH 77.5.21.7. A, Exhalant surface of the choanosomal skeleton of dicranoclone desmas; B, C, Details of dicranoclone desmas on the exhalant surface; D, E, Inhalant surface of dicranoclone desma skeleton, note smooth ectosomal dichotriaenes in situ in E; F, Details of dicranoclone desma sculpture.

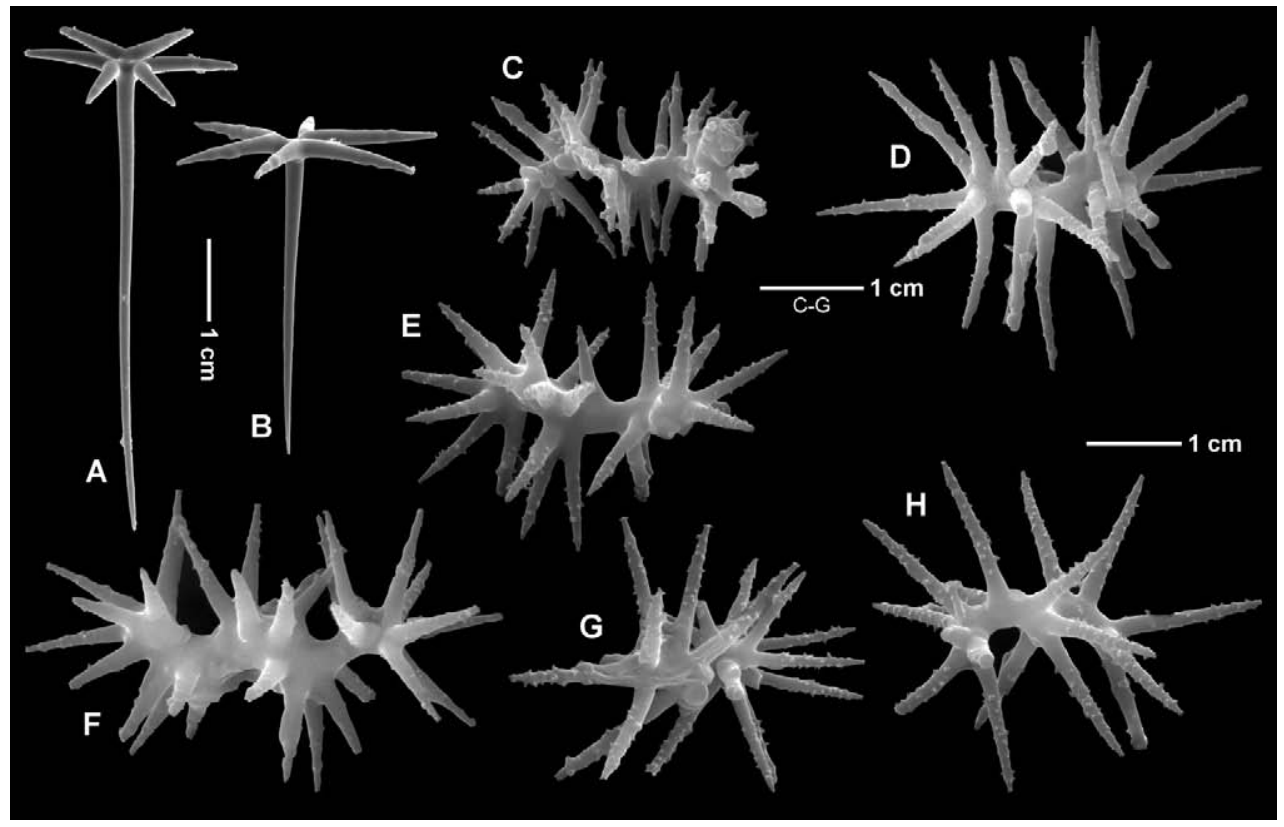

FIG. 9. - Corallistes masoni (Bowerbank, 1969), holotype BMNH 77.5.21.7. A, B, Ectosomal dichotriaenes; B-H, Choanosomal spirasters. 

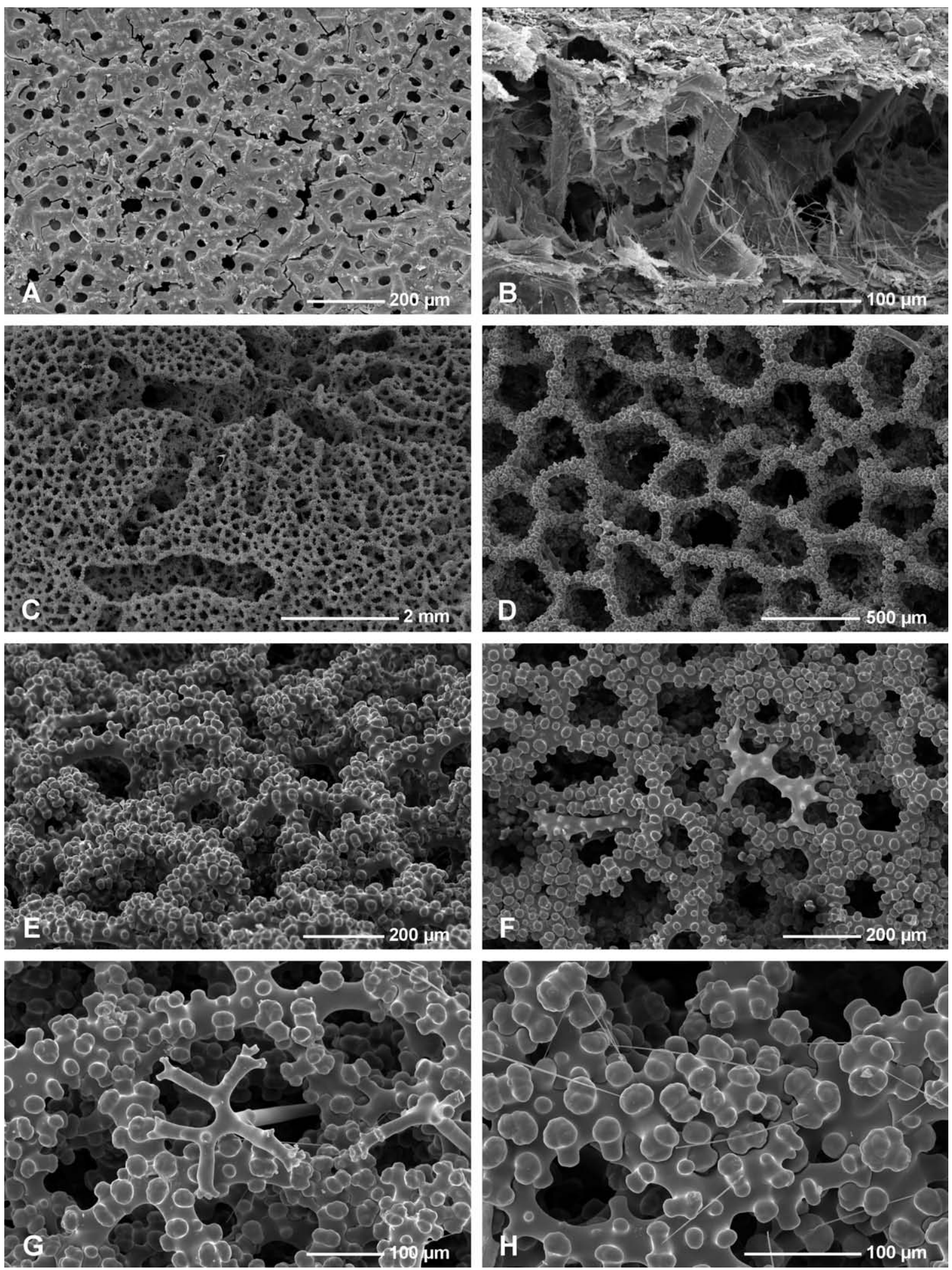

FIG. 10. - Neophrissospongia nolitangere (Schmidt, 1870), 3PP cave MNHN-DJV-121, (16/09/1991);. A, Natural inhalant surface view, note numerous ostia and ectosomal dichotriaenes; B, Transverse section of the ectosomal region (surface at the top), note large subdermal cavities with numerous microtylostyles; C, Exhalant surface of the choanosomal skeleton of desmas; D, Inhalant surface of the choanosomal dicranoclone desma skeleton; E, Oblique view of the exhalant surface of the choanosomal skeleton of dicranoclone desmas; F, Top view of the dicranoclone desma skeleton of the exhalant surface, with young desma only partly articulated with the rest of the skeleton; G, Ectosomal spinose dichotriaene in situ; H, Details of dicranoclone desma articulation and sculpture. 


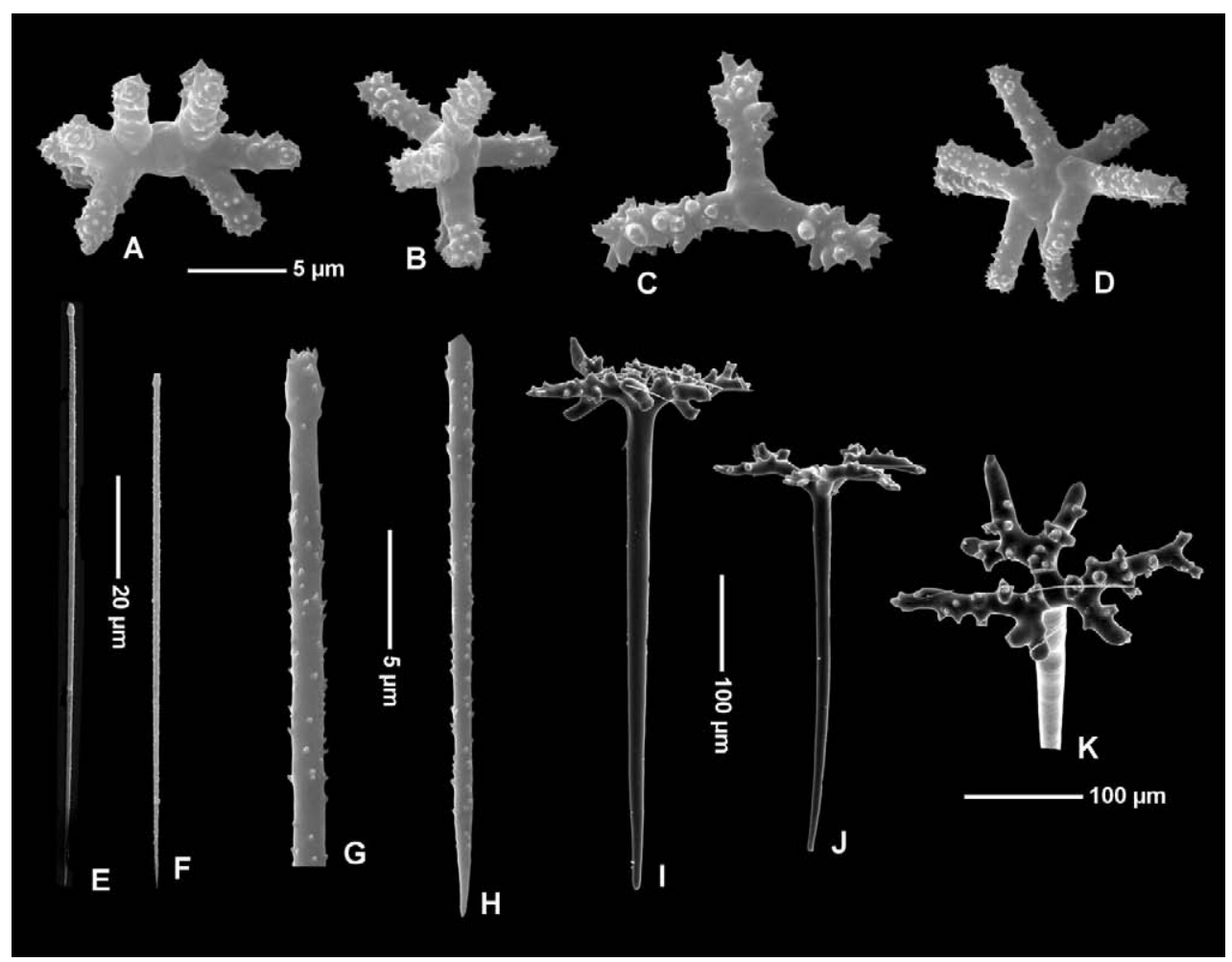

FIG. 11. - Neophrissospongia nolitangere (Schmidt, 1870), 3PP cave MNHN-DJV-121 (16/09/1991). A-D, Spirasters-streptasters; E-H, Spinose choanosomal microtylostyles: complete spicules (E, F), details of the upper part of the spicule with narrow spinose head (G), details of pointed end of the spicule $(\mathrm{H})$; Lateral views (I-J) of ectosomal dichotriaenes and oblique view $(\mathrm{K})$ in order to show the tuberculate/spinose cladome.

Remarks. In the diagnosis of this genus Pisera and Lévi (2002a) omitted the presence of microtylostyles among microscleres. A re-examination of the type material revealed that they are rare but present. This fact, as well as the discovery of new forms with different morphology, is the reason for emending the genus diagnosis.

Neophrissospongia nolitangere (Schmidt, 1870) (Figs. 2C-G, 10-12, Table 1)

Corallistes nolitangere Schmidt, 1870: 23, P1. 3, Fig. 6; Sollas, 1888: 339; Topsent, 1904: 59, Pl. 9, Fig. 11.

Corallistes bowerbanki (Johnson, 1863); Topsent, 1892: 51, Pl. 8: Fig. 2.

Corallistes masoni (Bowerbank, 1869); Chombard, 1998: 52, 55, Figs. 2I-J, 5-6; Chombard et al., 1998: 355, Fig. 2I-J. Neophrissospongia nolitangere; Pisera and Lévi, 2002a: 317, Figs. 9-11.

Material. Specimens N $N^{\circ}$, 3PP cave - 16/09/1991, MNHNDJV-121; No.9, Gaméou cave -25/9/1992, MNHN-DJV-122; $\mathrm{N}^{\circ} .14$, 3PP cave $-31 / 03 / 1998$, MNHN-DJV-123; $\mathrm{N}^{\circ}$. 23, 3PP cave - 16/09/1991.

Other material examined. Corallistes nolitangere, holotype MZUS PO 157, Neophrissospongia nolitangere, ZMA POR 19967 (Azores, somewhat SW of Princess Alice Bank, $400 \mathrm{~m}$ depth).

Emended diagnosis (after Pisera and Lévi, 2002a). Ear- or cup-shaped when young to large flabellate masses when old; cladome of ectosomal dichotriaenes covered with vertical tubercles/spines, simple or poorly branched; desmas strongly tuberculated dicranoclones forming a net-like structure; microscleres spirasters/streptasters with massive arms, and spinose microtylostyles.

Description. Ear-shaped when young, to irregular cup-shaped when larger, with walls about $1.7 \mathrm{~cm}$ thick, and attached to the hard substrate with entire lower part. Colour clear brown in life and in alcohol. Outer inhalant surface with numerous densely distributed ostia, 30-40 $\mu \mathrm{m}$ in size. Inner surface smooth except for several oscular openings located on small elevations about 1-2 mm across. Ectosome on both sides densely packed with dichotriaenes and thick crust of massive astrose microscleres (Fig. 12). Below the tangential rays of dichotriaenes there are large subdermal cavities with surface covered with microstyles; in the choanosome those microstyles are radially arranged (Fig. 12B). Choanocyte chambers rarely visible in our material. Abundant, large granular cells, $30 \mu \mathrm{m}$ in diameter with a $5 \mu \mathrm{m}$ diameter nucleus in the choanosome.

Choanosomal skeleton made of massive and strongly tuberculated rather linear dicranoclones, forming irregular net-like structure with irregular net openings up to $0.5-0.6 \mathrm{~mm}$ wide. Skeletal net denser on the exhalant surface. Sinuous, radially arranged canals occur at the surface of the choanosomal skeleton, on the oscular side, leading to oscules. Dicranoclone desmas, approx- 

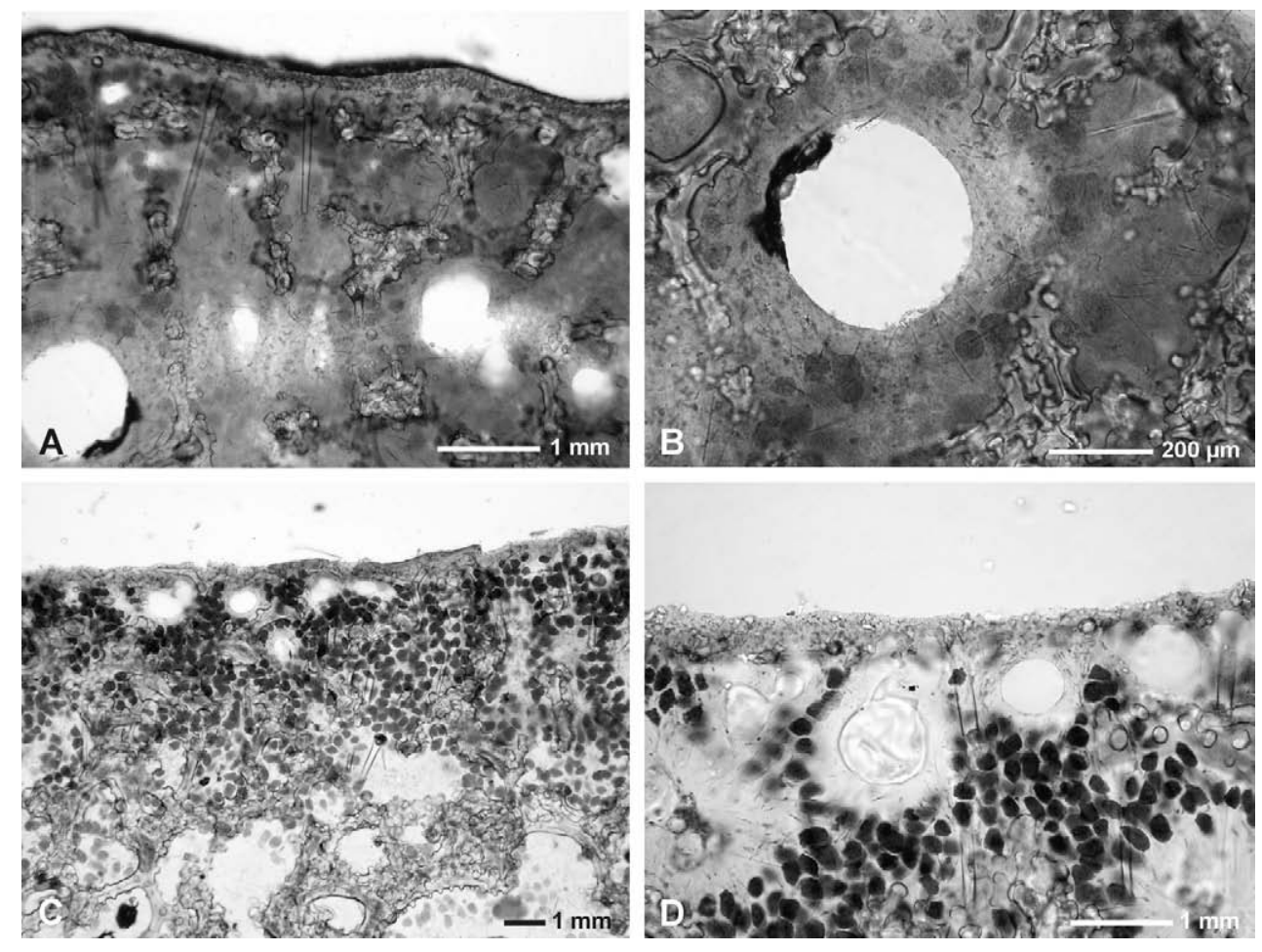

FIG. 12. - Neophrissospongia nolitangere (Schmidt 1870). A, B, Section of the ectosome and choanosome stained with acid fuchsin, 3PP cave, MNHN-DJV-123 (31/03/98), note thick layer of streptasters/spirasters in the ectosomal region, spinose dichotriaenes with long rhabdomes penetrating deeply the choanosome with dicranoclone desmas (A) and details of choanosome with large granular cells, dicranoclone desmas and more or less radially oriented microstyles visible around a canal (B); C, D, Section of the ectosome and choanosome stained with acid fuchsin, (MNHN-DJV-122, 25/09/1992), note densely distributed granular cells in the subectosomal region; note dense layer of ectosomal microscleres in (D).

imately 289-382 $\mu \mathrm{m}$ in size, very massive and densely covered with high, more or less mushroom-shaped tubercles which may divide into smaller low elevations. The desmas are very tightly articulated.

Ectosomal dichotriaenes with rhabdome 313-800 x 15-30 um, sometimes slightly curved or flexuous, generally with a blunt point, and cladome 160-313 $\mu \mathrm{m}$ in diameter. The cladome, which bears numerous loosely spaced irregular pointed tubercles, may show in addition irregular branches which cause a slight resemblance to phyllotriaenes. However, axial canals extend to all the cladome rays, clearly pointing to their dichotriaene, and not phyllotriaene (where axial canals are very short and limited to the centre of cladome only) nature.

Microscleres of two types. The first type are spirasters/streptasters with thick arms covered with numerous massive pointed spines, which occur mostly from the half-length to their tips; they are 8.4-15.4 $\mu \mathrm{m}$ long and 6.1-12.9 $\mu \mathrm{m}$ large. The second type are spinose microtylostyles, with narrow and elongated heads which are also spinose, with spines along the spicules directed toward the head and rather sparsely distributed; they are 74-137 long x 1.4-2.1 $\mu \mathrm{m}$ large.

Remarks. The examination of the specimen used by Chombard (1998, see also Chombard et al., 1998) in her molecular studies and determined as C. masoni (Bowerbank, 1869) revealed that it is in fact Neophrissospongia nolitangere. The specimens of this species are usually ear- to irregular cup-shaped, but a recently collected specimen from the Azores (personal information from Joana Xavier, specimen ZMA POR 19967) attains a very large size (about $1 \mathrm{~m}$ in diameter and $40-50 \mathrm{~cm}$ in height) and forms folded lamellate masses.

Occurrence. 3PP cave (80-100 $\mathrm{m}$ from the cave opening, attached to vertical walls, 20-22 m depth, in a water mass with a nearly constant temperature, $c a .13$ to $15^{\circ} \mathrm{C}$ ) and Gaméou cave (25/9/1992).

Distribution. Off Portugal, Azores, Cape Verde Islands.

\section{Neophrissospongia endoumensis $\mathrm{n}$. sp.} (Figs. 2H-J, 13-15, Table 1)

Holotype. Specimen no. MNHN-DJV-120 147S, here illustrated Fig. 2H-J.

Material. One specimen $\left(\mathrm{N}^{\circ}\right.$ 2) 26/02/1980 from the Endoume cave $43^{\circ} 16^{\prime} 47.3^{\prime \prime} \mathrm{N}, 005^{\circ} 21^{\prime} 00.3^{\prime \prime} \mathrm{E}$, preserved in ethanol.

Etymology. From Endoume, the type locality, a few metres from the Marine Laboratory in Marseille, France. 

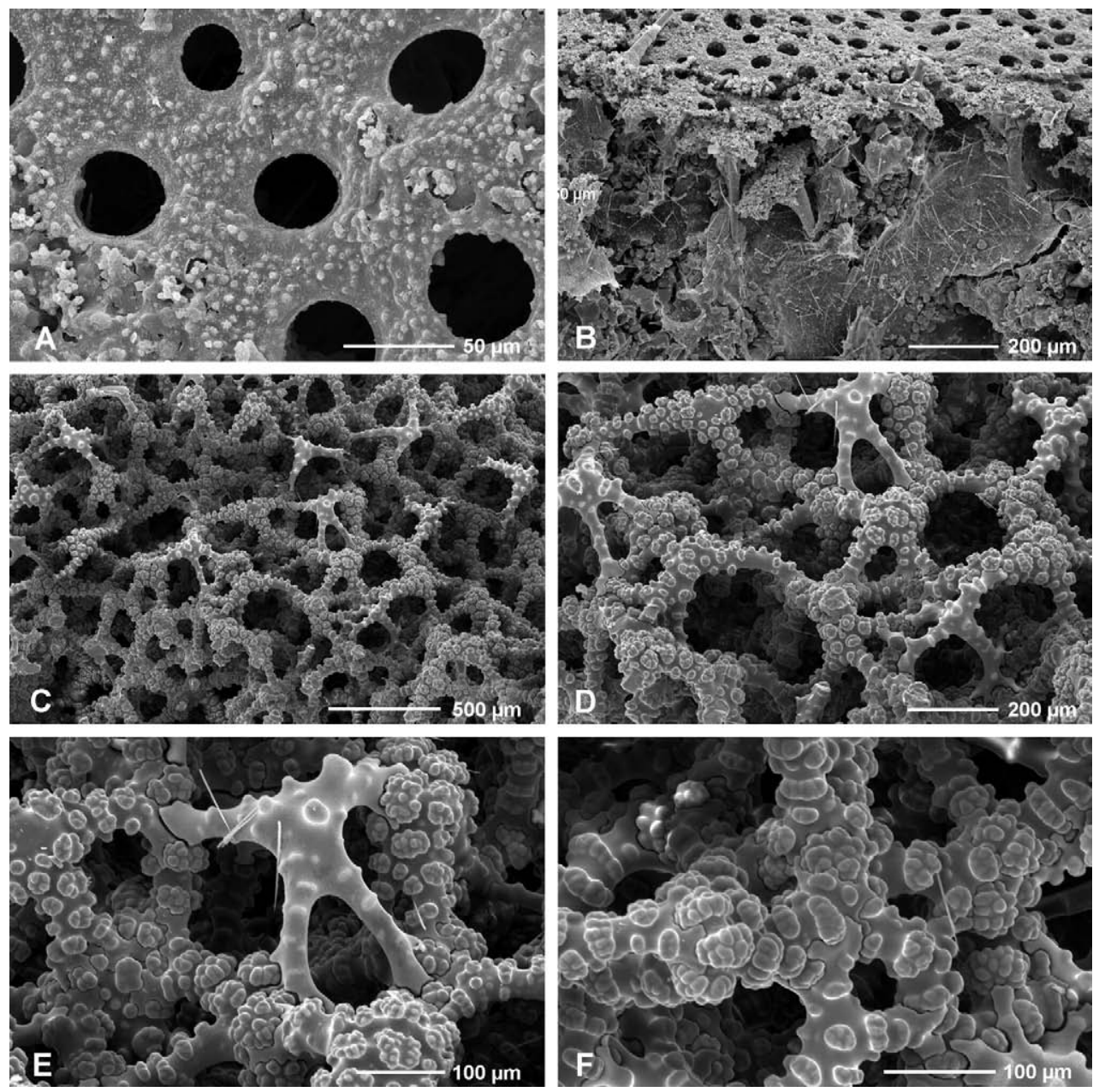

FIG. 13. - Neophrissospongia endoumensis n. sp. holotype MNHN-DJV-120. A, Details of ectosome of the outer inhalant surface, with a dense crust of spiraster microscleres; B, Transverse section of the ectosomal region (inhalant surface at the top), showing large subdermal cavities with numerous microtylostyles; C, Surface view of the choanosomal skeleton, with several young desmas; D, Details of the choanosomal skeleton of dicranoclones; E, Young dicranoclone articulating to older desmas; F, Details of dicranoclone articulation and ornamentation.

Diagnosis. Cup-shaped Neophrissospongia with oscular openings on the upper side. Ectosomal dichotriaenes with very massive, thick and irregular, tuberculated cladome. Choanosomal dicranoclones very massive with a central core, strongly tuberculate; arms bearing ring like sculpture. Two types of microscleres: massive spirasters/streptasters with short, thick spines, and slightly spinose microtylostyles.

Description. Small, cup-shaped sponge with thick walls, $25 \times 20 \mathrm{~mm}$ large and $15 \mathrm{~mm}$ high, slightly oval in cross section. Walls about $6 \mathrm{~mm}$ in thickness, with rounded edges. The single studied specimen was attached to a subhorizontal rocky substrate by its entire base. Upper concave surface bearing several oscular openings, about $0.7 \mathrm{~mm}$ wide located on small elevations $1-2 \mathrm{~mm}$ in diameter. Outer inhalant surface with numerous round ostia 23-54 $\mu \mathrm{m}$ in diameter and with a dense crust of microscleres (spirasters/streptasters). Below the outer surface large subdermal cavities lined with numerous microtylostyle microscleres.
Ectosomal dichotriaenes with massive cladomes (248-283 $\mu \mathrm{m}$ in diameter), irregular at first sight and thus resembling phyllotriaenes, but with the axial canals extending along all main branches up to their tips. This irregularity of the cladome follows from the fact that the main branches further ramify, producing irregular, densely packed side branches with spine-like tips. Upper surface of the cladome covered with numerous densely packed, vertically pointed, spine-like tubercles. Rhabdome rather thick, sometimes slightly flexuous, often with a few swellings, with a blunt or round end: $320-615 \times 32-45 \mu \mathrm{m}$.

Choanosomal skeleton made of strongly tuberculated, massive dicranoclones approximately 318-490 $\mu \mathrm{m}$ in size. Desmas very tightly articulated and forming irregular meshes. Dicranoclones with a central massive core from which 3-5 arms extend downwards. They are very densely covered with complex low tubercles, round in the centre of the desma but heavily ornamented with smaller and low rounded tubercles. On the arms of dicranoclones the main tubercles may join, 

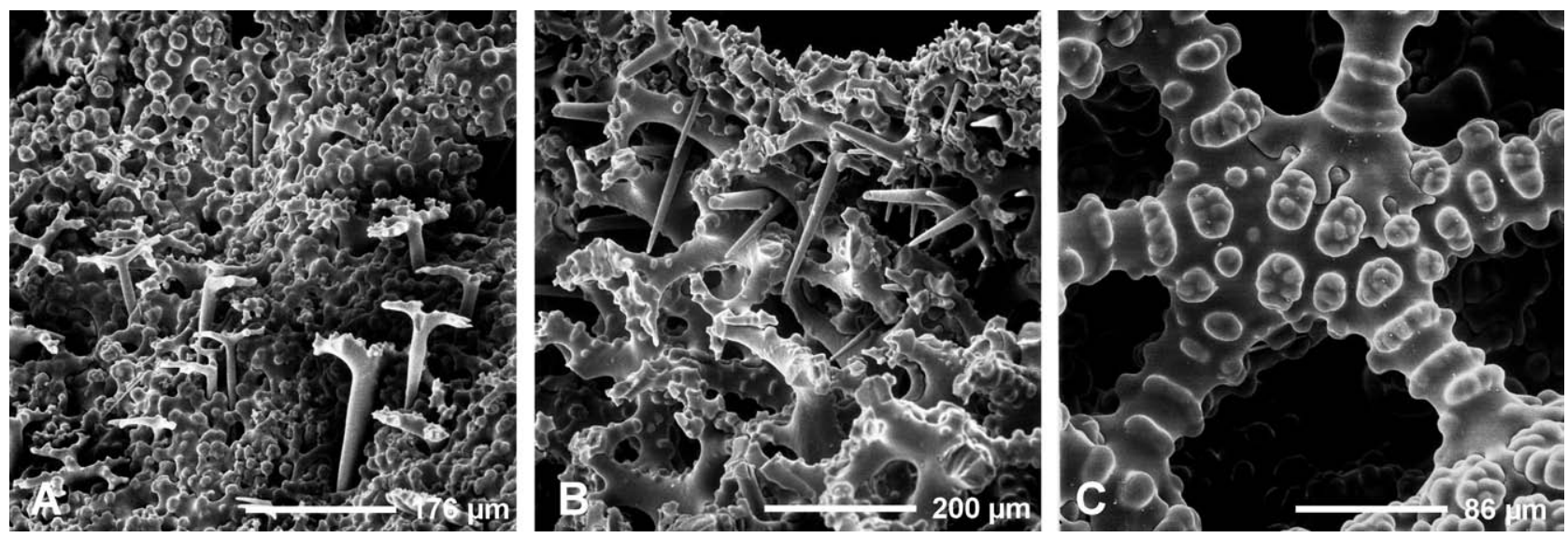

FIG. 14. - Neophrissospongia endoumensis n. sp., holotype MNHN-DJV-120. A, B, Dense choanosomal skeleton from the lower part of the sponge in surface (A), and cross section view (B), note ectosomal dichotriaenes in situ; C, Details of the choanosomal dicranoclone desmas sculpture and articulation.

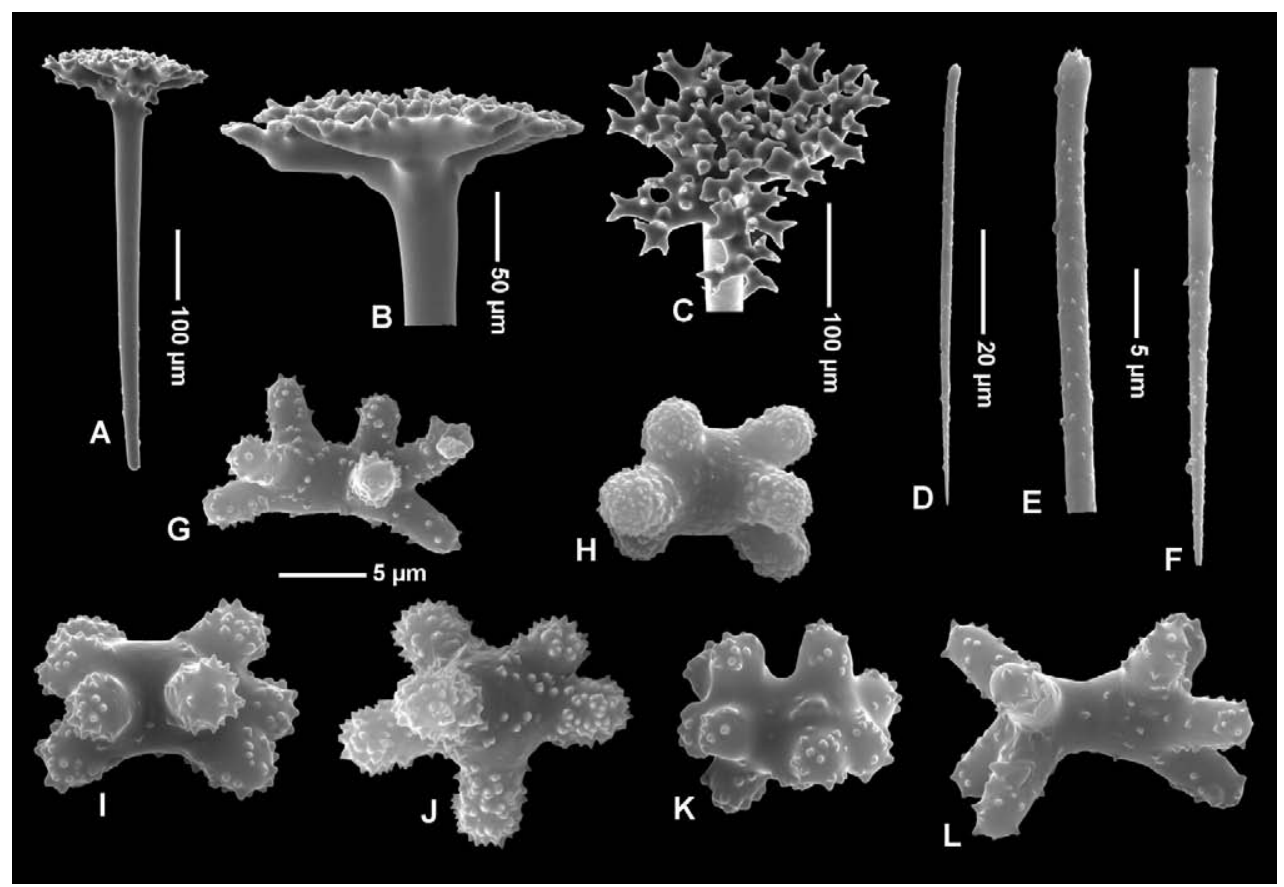

FIG. 15. - Neophrissospongia endoumensis n. sp., holotype MNHN-DJV-120. A-C, Ectosomal dichotriaenes; D-F, Choanosomal microtylostyles, general view (D), head (E), and lower (F) part views; G-L, Thick spirasters/streptasters from the ectosomal region.

forming ring like structures, also ornate with smaller rounded tubercles.

Microscleres of two types. Type I a massive spiraster/streptaster, 12.7-20.1 x 11.4-16.6 $\mu \mathrm{m}$, with short and thick arms covered with triangular low spines, occurring in the ectosome. Type II a spinose microtylostyle, 68.8-123 x 1.6-1.7 $\mu \mathrm{m}$ with the head only slightly marked, occurring in subdermal cavities and in the choanosome.

Remarks. This species differs from the most morphologically similar $N$. nolitangere in details of spiculation. In N. endoumensis n. sp. dichotriaenes are much more massive and have more irregular cladomes with numerous branches with densely distributed spines, and form a dense, canopy-like surface, while in N. nolitangere clades are less branched and stay separate, having also less densely distributed ornamentation. In $N$. endoumensis the rhabdomes of dichotriaenes are conical, blunter and thicker. Also spirasters/ streptasters are different, i.e. more regular and massive in $N$. endoumensis, and have shorter, massive arms that are rounded at their tips. The dicranoclone desmas are more massive and with a central part swollen in $N$. endoumensis, while in $N$. nolitangere they are rather linear. The choanosomal skeleton of $N$. nolitangere displays a regular net with large meshes in the inhalant surface not observed in $N$. endoumensis.

This species differs from the encrusting $N$. nana Manconi and Serusi (2008) in being cup- 

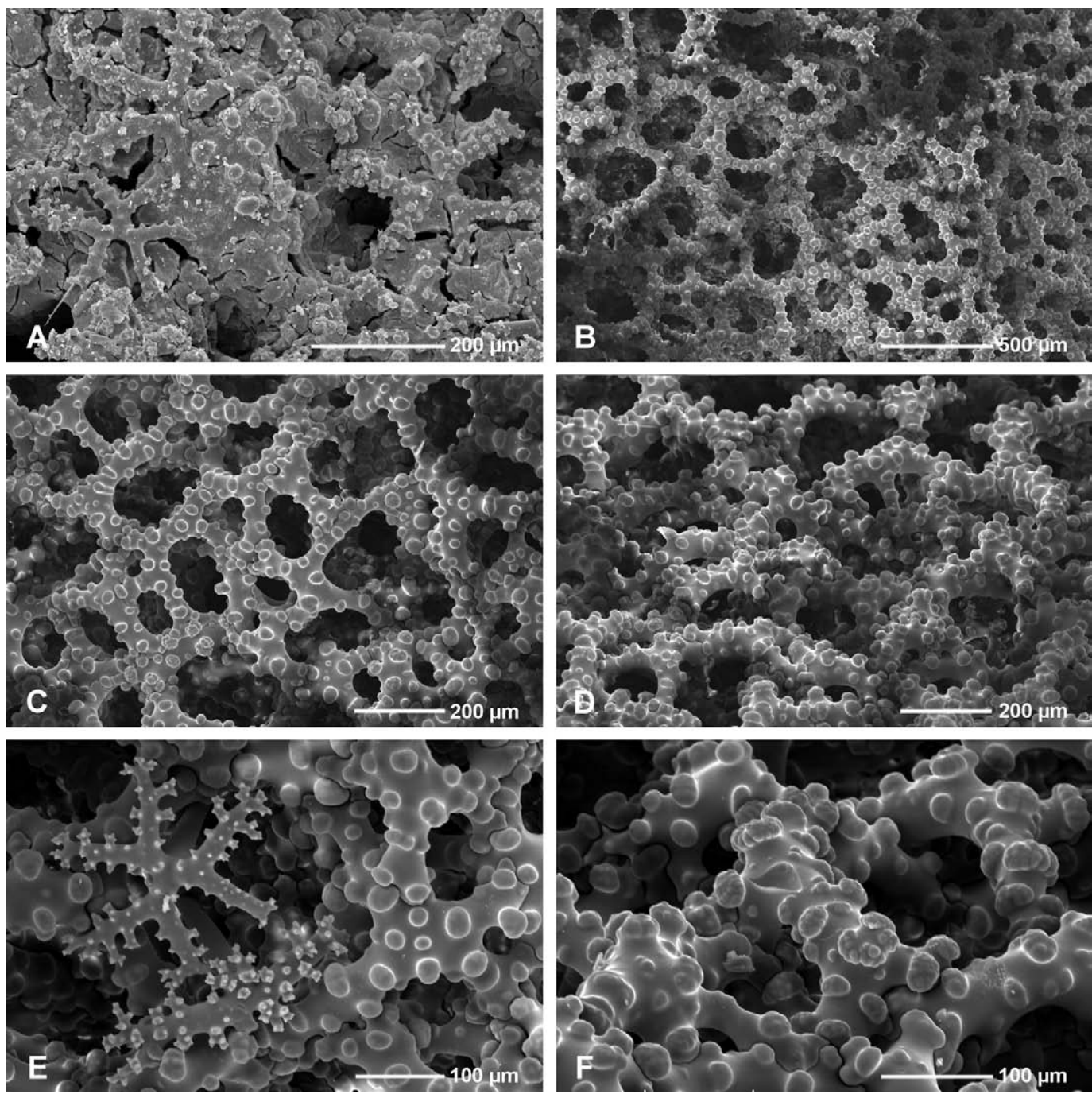

FIG. 16. - Neophrissospongia radjae n. sp., holotype MNHN-DJV-119. A, Natural surface of the ectosome with tuberculate dichotriaenes; B, Surface of the choanosomal dicranoclone desma skeleton; C, D, Details of choanosomal skeleton of dicranoclone desmas in top (C), and oblique (D) views; E, Ectosomal dichotriaene in situ; F, Details of the articulation and sculpture of the dicranoclone desmas.

shaped and in having massive, strongly tuberculated desmas, while $N$. nana has slender desmas, with tubercles bearing smooth heads, which form a loose network. Also, the ectosomal dichotriaenes in $N$. endoumensis are more massive, with a much more branched tuberculated cladome than in $N$. nana. The microscleres of $N$. endoumenis have larger size on average and spirasters/amphiasters are massive, more regular and with shorter rounded arms.

From $N$. radjae n. sp., which is club-shaped with one narrow spongocoel located at the top of the sponge, $N$. endoumensis differs in being cup-shaped, and in some details of spiculation (see descriptions and remarks to $N$. radjae below).

Occurrence. Endoume cave, attached to a subhorizontal rocky surface, $5 \mathrm{~m}$ depth, under dim light condition approximately $5 \mathrm{~m}$ from cave opening.

\section{Neophrissospongia radjae $\mathrm{n}$. sp.}

(Figs. 2A-B, 16-17, Table 1)

Holotype. Specimen no. MNHN-DJV-119 (dry specimen), here illustrated Fig. 2A-B.

Material. A single specimen (MNHN-DJV-119) from a Dalmatian cave (Croatia), Island of Korkula (the town of Korkula is $\left.42^{\circ} 57^{\prime} 16.26^{\prime} \mathrm{N}, 17^{\circ} 07^{\prime} 52.21^{\prime \prime} \mathrm{E}\right)$.

Etymology. From the name of the diver, Tonci Radja who had collected this species.

Diagnosis. Neophrissospongia clavate in morphology, with narrow, centrally located spongocoel. Ectosomal dichotriaenes simple, with tuberculated cladome. Microscleres massive spirasters and microtylostyles.

Description. Small clavate sponge about $45 \mathrm{~mm}$ high and $30 \mathrm{~mm}$ in diameter, clear brown in alcohol. It 
is polygonal in cross section, resulting from the presence of flattened to slightly concave areas, separated by low rounded and wide ridges, on lateral surfaces of the sponge. The concave areas, being inhalant, are finely porous. The sponge summit is concave with two closely located oscular openings which are about 1.5 $\mathrm{mm}$ wide. The attachment base is about $19 \mathrm{~mm}$ wide. In a preparation there is a thick layer of microscleres in the ectosome.

Ectosomal dichotriaenes simple (without additional branching except at their tips) and regular, bearing on the upper surface of the cladome massive tubercles usually divided into smaller tubercles or thick pointed spines. Rhabdome 220-639 x 20-30 um, with a blunt or acerate end. Cladome 160-340 $\mu \mathrm{m}$ in diameter.

Choanosomal desmas typical dicranoclones, 280$500 \mu \mathrm{m}$ in diameter, forming an irregular net-like structure, with rather sparsely distributed round tubercles which may be ornate with smaller secondary tubercles.

Microscleres of two types. In the ectosome, thick spirasters/streptasters (forming a thick layer) with blunt arms covered with irregular, usually pointed tubercles, 9.55-15.5 $\mu \mathrm{m}$ long and 8.35-12 $\mu \mathrm{m}$ wide. In the choanosome, feebly, irregularly spinose microtylostyles 80-140 x 0.8-2.1 $\mu \mathrm{m}$.
Remarks. Although rather similar in spicular characters to $N$. nolitangere, the new species, which is a massive, club-like sponge with a centrally located osculum, differs completely in morphology from $N$. nolitangere, which is an ear-shaped or shallow cup-shaped sponge when young and may form large folded masses when old (Joana Xavier, Amsterdam, pers. info.). The two species differ also in details of desmas and microscleres: spirasters are much more massive in $N$. radjae than in $N$. nolitangere, as are the cladomes of dichotriaenes, which are also more regularly built in the new species.

This species differs from $N$. endoumensis n. sp. in the clavate habitus. In $N$. endoumensis the rhabdome of dichotriaenes is more blunt and thicker, while the cladome is more massive and very densely covered with spines that are rather triangular in $N$. endoumensis and massive-irregular in $N$. radjae $n$. sp. Spirasters also differ slightly, being less regular and with longer arms than in $N$. endoumensis. Desmas of $N$. radjae are less thick (massive) and more linear than in N. endoumensis, where they are much thicker (massive) with a central swollen part, and are more densely covered with thicker and more complex tubercles.

Occurrence. A cave of the island of Korkula (exact location unknown), on the Dalmatian coast of the Mediterranean Sea (Croatia).

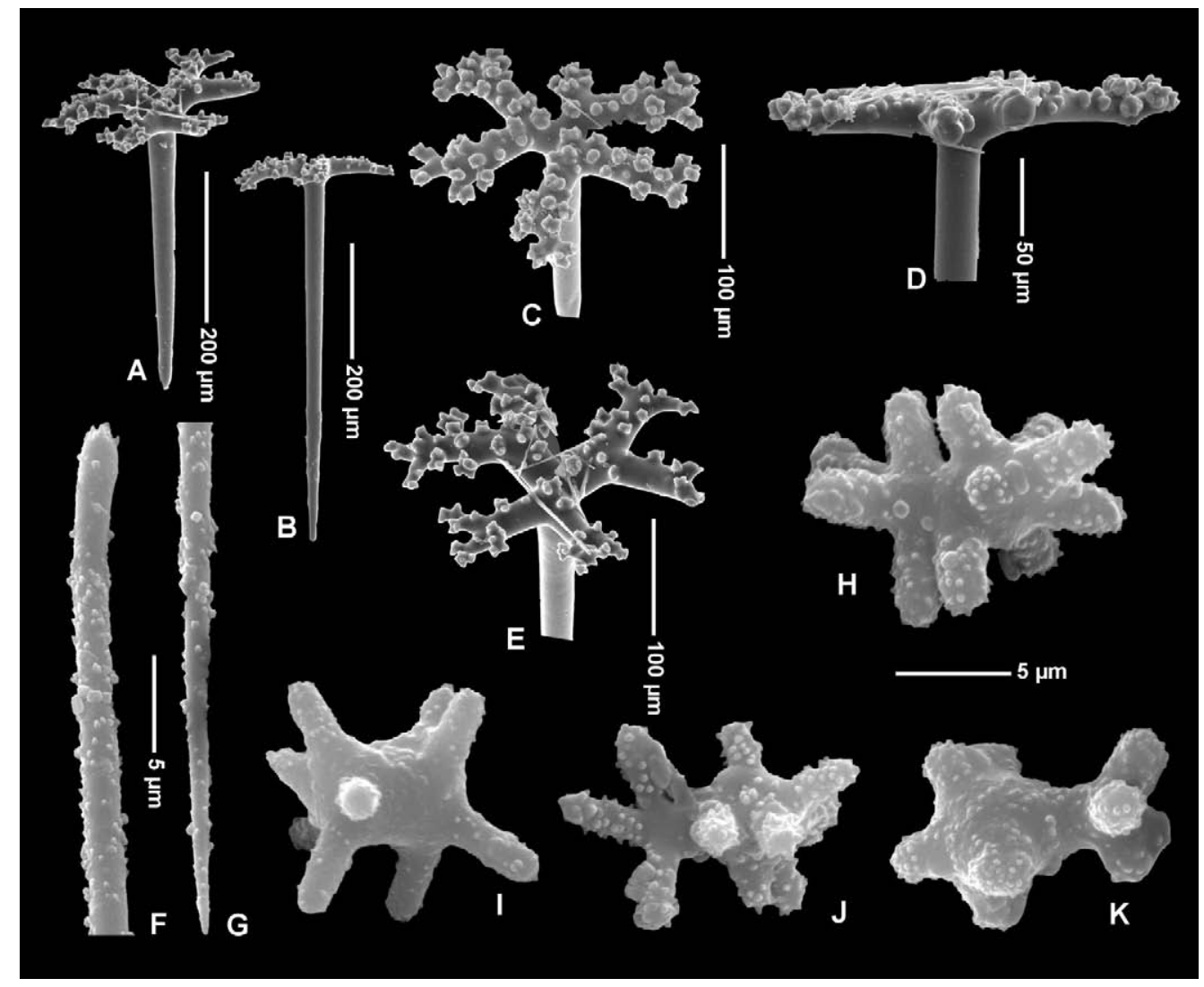

FIG. 17. - Neophrissospongia radjae n. sp., holotype MNHN-DJV-119. A-E, Ectosomal tuberculate/spinose dichotriaenes; A, B, Complete spicules in lateral view; C-E, Details of tuberculate/spinose cladome; F, Head and an extremity of spinose microtylostyle; G-J, Thick spirasters from the ectosomal region. 
Family TheonelLidAe Lendenfeld, 1903

Genus Discodermia du Bocage, 1870 1869.

Type species. Dactylocalyx polydiscus Bowerbank,

Diagnosis (emended after Pisera and Lévi, 2002b, and Kelly, 2007). Polymorphic: massive, cup-shaped, branched, cylindrical. Ectosomal spicules exclusively discotriaenes; choanosomal spicules are regular to irregular tetraclone desmas that may be smooth or tuberculate; other choanosomal spicules are long oxeotes or stylotes; microscleres are acanthoxeas and smaller acanthorhabds.

\section{Discodermia polymorpha $\mathrm{n}$. sp.}

(Figs. 18-23, Table 2)

Discodermia polydiscus (Bowerbank, 1869); Pouliquen, 1969a: 43, Pl. 8, Fig.1, Pl. 12, Fig. B; Pouliquen, 1972: 749, Pl. 9, Fig.1, Pl. 10, fig.C; Vacelet, 1969: 164, Fig. 2.

Material. Numerous specimens from various Mediterranean caves. France, Marseille area: 3PP cave, numerous specimens; Trémies cave, common; Gaméou cave; Cap Morgiou cave; Figuier cave; Jarre III cave. Spain: Medes Islands, Dolphin cave. Croatia: cave no. 3; Kornat Island, pits in cove Kravljačica; cave no 4. Dugi Otok, Brbinjšćica cove. Bathyal zone: Aegean Sea, 360 m.

Holotype. Specimen ZPAL Pf.21/1, here illustrated Fig. 18B (3PP cave). Paratypes. Specimens no. ZPAL Pf.21/2, here illustrated Fig. 18C, specimen ZPAL Pf.21/3, specimen MNHN-JV, $\mathrm{N}^{\circ} 14$ (all 3PP cave), ZPALPf.21/B670 here illustrated Fig. 18D (cave no. 3, pit in cove Kravljačica, island Kornat). Specimen MNHN-DJV-127, Aegan Sea. Specimen MNHN-DJV-128, Jarre cave (here illustrated Fig. 18I). Specimens MNH-DJV-129, 3PP cave.

Other material examined. Discodermia polydiscus (Bowerbank), Holotype, NHM 40.10.23.12 (dry specimen and slides).

Etymology. From Latin polymorpha - multishaped, referring to high variability of morphology and spicules of the species.

Diagnosis. Small polymorphic Discodermia, varying in shape from nearly spherical to irregular masses with protuberances. Oscula grouped in poorly defined fields or individually dispersed. Ectosomal discotriaenes very variable, from perfectly circular and concave to oval with irregular outline. Choanosomal desmas smooth tetraclones. Microscleres spinose microxeas and microrhabds.

Description. Polymorphic sponges more or less spherical (especially when young), attached to the substrate by a short pedicel or by their entire surface, growing to irregular masses with short protuberances, up to $57 \mathrm{~mm}$ in diameter. Surface smooth, entirely covered with ectosomal discotriaenes. Oscula up to 100 $\mu \mathrm{m}$ in diameter, dispersed or in irregular fields.

Ectosomal discotriaenes with a short rhabd (60-65 $\mu \mathrm{m}$ long) and a slightly concave disc, varying in shape from perfectly circular in some specimens to circular with irregular margins, and to completely irregular. Ectosomal discotriaenes are very tightly packed, often strongly overlapping, except in the specimen from the Aegean Sea, where they are loosely packed, usually not touching each other and the areas between them are infilled with a thick crust of microscleres. Discotriaene diameter strongly variable, from 174 to $366 \mu \mathrm{m}$, between various areas of the same sponge, as well as between various specimens from the same cave and/ or various caves. However, no consistent pattern of this variability has been observed (see Table 2 and Fig. 19A, C, E, G, Fig. 20A, C, E, G, and Fig. 21 for details).

Choanosomal desmas smooth, rather irregular tetraclones with poorly branched tips by which they articulate with each other, 370-718 $\mu \mathrm{m}$ in diameter (Table 2). Choanosomal skeleton rather irregular, differing strongly in regularity and degree of desma articulation (see Fig. 19B, D, F, H, Fig. 20 B, D, F, H), between various caves and even between specimens from the same cave. Particular tetraclones differ also in size and thickness of the clones, without any consistent trend allowing for differentiation of the various populations (except perhaps Dalmatian specimens). Canal openings in the choanosomal skeleton irregular and only slightly larger than normal skeletal meshes.

Microscleres of two types, both also very variable in shape (Figs. 22, 23). Spinose microxeas, in some cases centrotylote $24.80-68.30 \times 1.66-3.78 \mu \mathrm{m}$. Acanthorhabds varying from cylindrical to fusiform, 13.2037.20 (43.90) x 1.85-4.25 90 (5.02) um (Table 2).

Remarks. The genus Discodermia is a difficult one because it has few and very variable characters useful for species differentiation. The studied material from various submarine Mediterranean caves is a good example of the problems encountered in the taxonomy of this genus. The shape of the various specimens is variable, as are the spicules, and molecular data are highly desirable to solve the problem of the species diversity of the genus in the Mediterranean.

We have decided to attribute all our specimens to one morphospecies, assuming that there is only one highly polymorphic species occurring in all the caves and in the bathyal zone. However, the possibility that different species could be distinguished in different areas of the Mediterranean cannot be excluded and should be tested by using molecular markers. Preliminary data obtained by Pierre Chevaldonné (pers. comm.) with $\mathrm{mt}$ COI and rDNA ITS-2 indicate no differences between specimens from the Medes Islands and several caves of the Marseille area. However, specimens from Croatia (Dugi Otok) display significant differences (indels) in their ITS sequences compared with those from the Medes and Marseille, a difference that is at present difficult to evaluate, particularly in the absence of sequences from $D$. polydiscus or D. ramifera.

The specimens that we attribute to this new species are very variable both in morphology (although sub- 


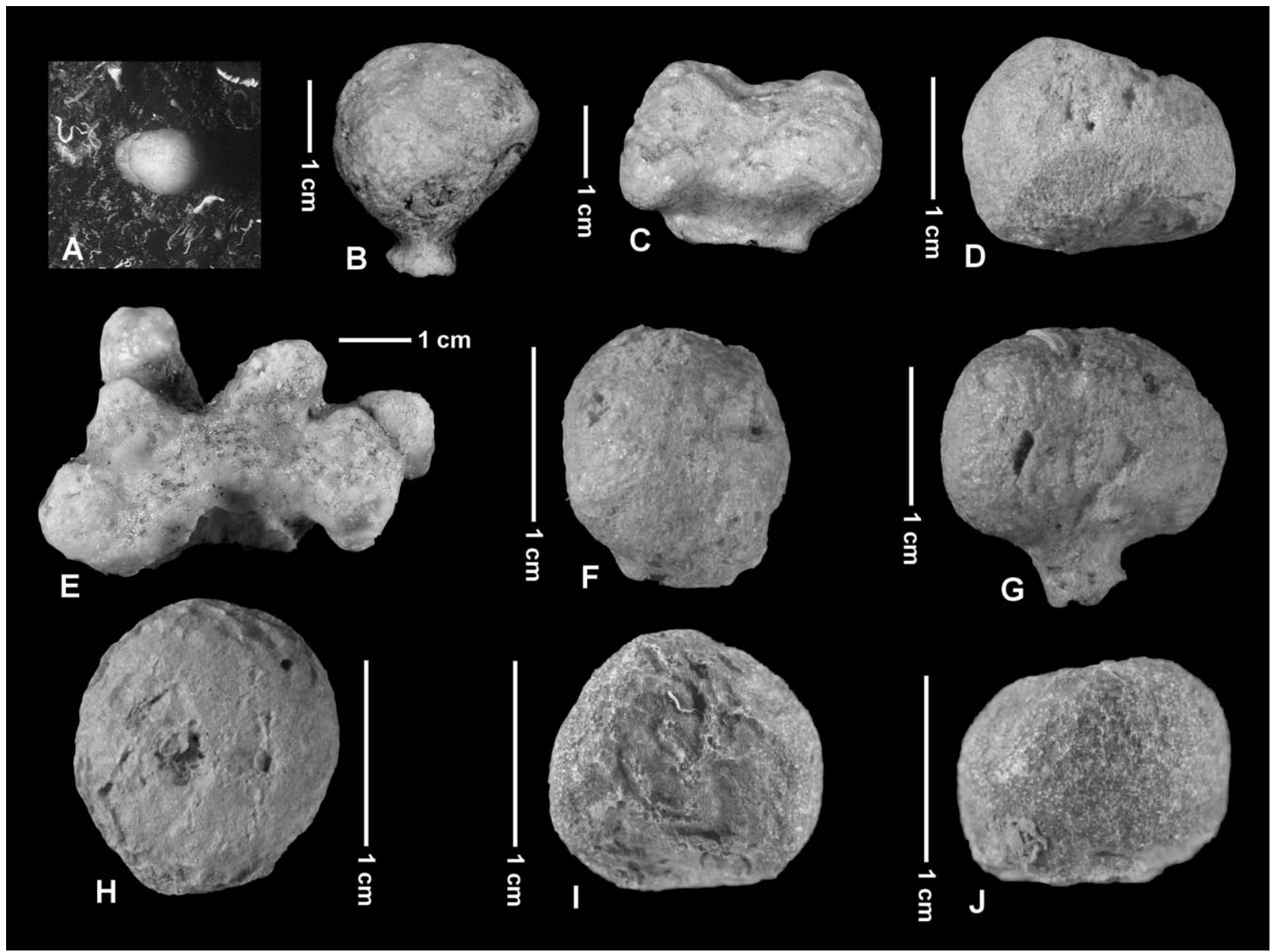

FIG. 18. - Discodermia polymorpha n. sp. Morphology of specimens from different caves. A, in situ, 3PP cave; B, Holotype, ZPAL Pf.21/1, 3PP cave; C, Paratype ZPAL Pf.21/2, 3PP cave; D, Paratype, cave no. 3, pit in cove Kravljačica, Island Kornat, ZPAL Pf.21/B670; E, Paratype, MNH JV., 3PP cave (specimen no. 14); F, G, Cave no.1, Lastovo, Ubli, Pasadur, ZPALPf.21/B579; H, Trémies cave (lateral view) ZPAL Pf.21/7; I, J, Jarre III cave, paratype MNHN-DJV-128, top view (I), , lateral view (J).

spherical forms are dominant) and in spicule characters. Our inability to find any discrete group or pattern in this variability justifies the present interpretation as a single, variable species. This polymorphism could be related to differences in cave environments, i.e. temperature, local silicic acid concentration, and nutrient levels, between particular caves or between the various cave parts. This problem can be studied in detail only with systematic collection of sponge specimens and study of local environmental parameters, which were not possible for this study.

Although polymorphic, these Mediterranean Discodermia specimens significantly differ from the two most closely related Atlantic species, D. polydiscus Bowerbank, 1869, to which the Mediterranean Discodermia have been previously attributed (Pouliquen, 1969a, b, 1972; Vacelet, 1969), and D. ramifera Topsent, 1892, and we propose to consider them as belonging to a new species. Discodermia polymorpha n. sp. is mostly spherical to irregular in shape, whereas $D$. ramifera is ramose and D. polydiscus is cup-shaped to irregular, with oscules located on eleva- tions, which is not observed in the new species. Both the Atlantic species have a larger size. The desmas of $D$. polydiscus and D. ramifera are smaller on average, more massive and with strongly branched/tuberculated zygomes, and form a denser skeleton than those of D. polymorpha $\mathrm{n}$. sp., which are relatively thin and poorly branched at zygomes. Discotriaenes, which are similar in size in the two species, are more variable in shape and often slightly incised in D. polymorpha, while they are oval to round in D. polydiscus. The same is true of microscleres: they are more variable in the new species than in D. polydiscus. Acanthorhabds are usually cylindrical and curved, only rarely massive to fusiform, and slightly longer in D. polymorpha, while they are as a rule massive cylindrical in D. polydiscus. Acanthoxeas are also rather cylindrical and never fusiform, usually thinner and slightly longer in $D$. polymorpha than in $D$. polydiscus. The specimen from the bathyal zone of the Aegean Sea fits the variability observed in cave specimens, and we consider it as belonging to the new species from shallow water caves. 

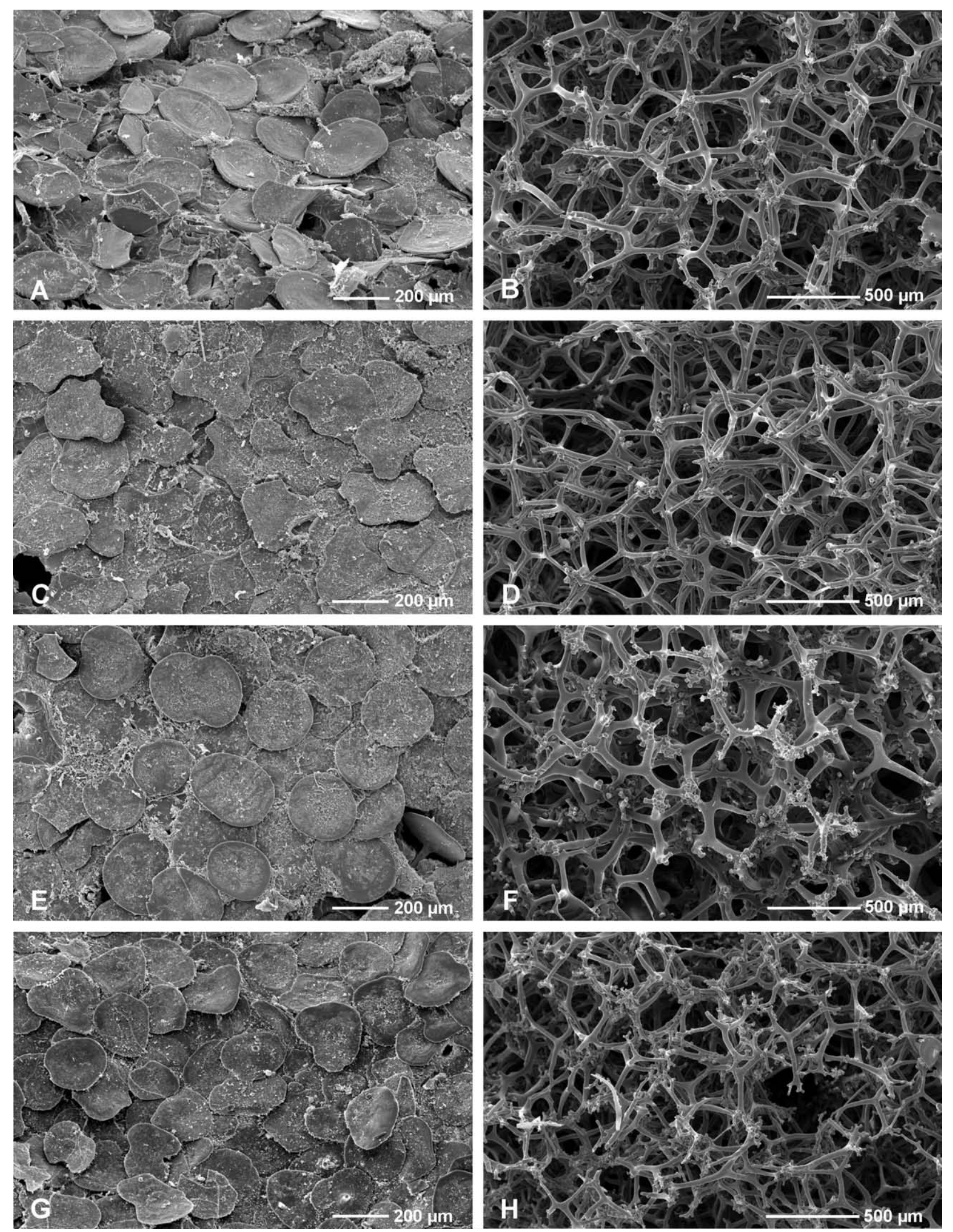

FIG. 19. - Discodermia polymorpha n. sp., ectosomal discotriaenes (A, C, E, G) and choanosomal desmas (B, D, F, H) from specimens from various caves, showing the variability of the skeleton (for details see Table 2). A- F, Different specimens from the 3 PP cave, A-B ZPAL Pf. 21/4, C-D ZPAL Pf.21/5, E, F, specimen 31/03/1998; G-H, Trémies cave ZPAL Pf.21/7. 

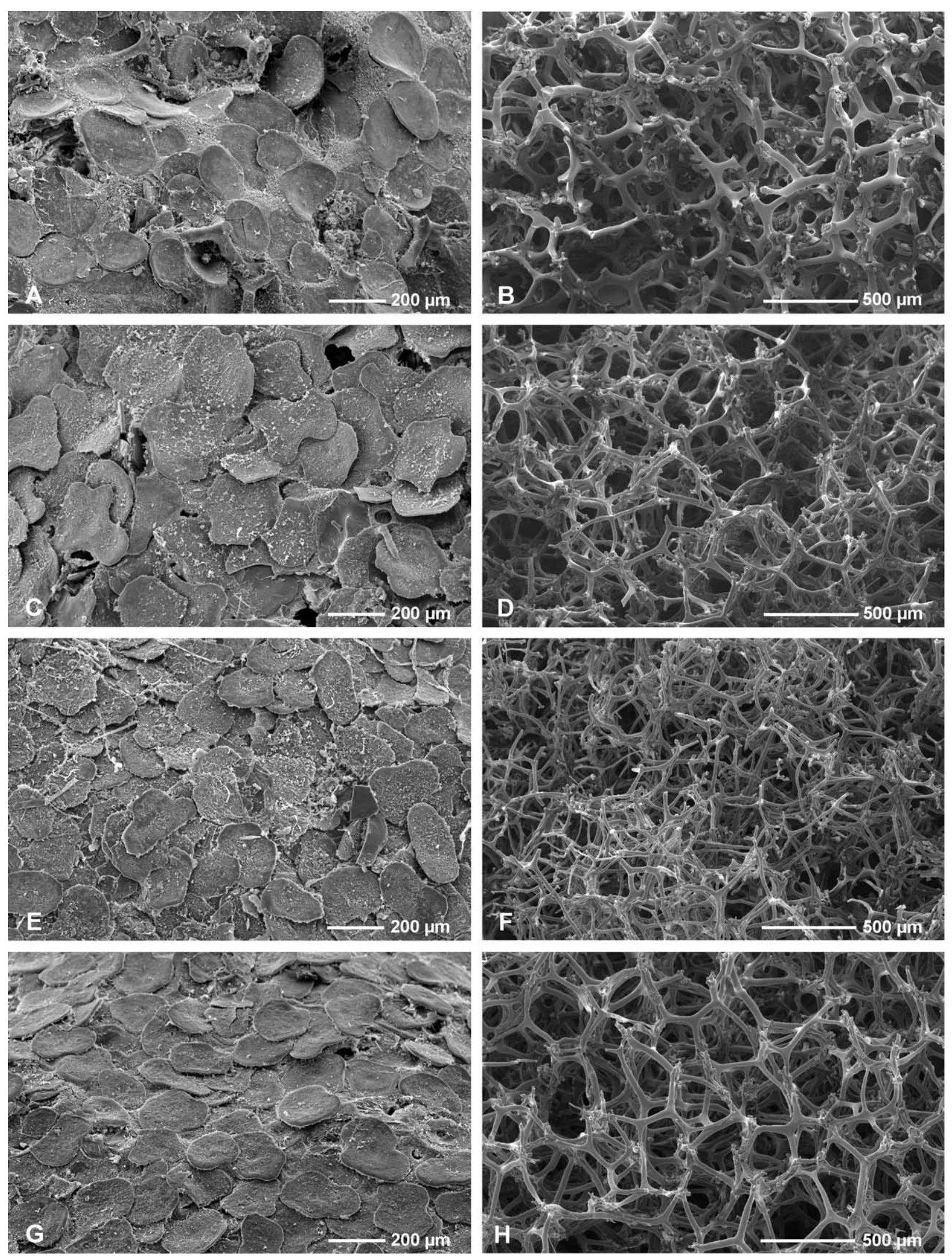

FIG. 20. - Discodermia polymorpha $\mathrm{n}$. sp. ectosomal discotriaenes and choanosomal desmas from various caves and deep water (Aegean Sea), showing the variability of the skeleton (for details see Table 2). A, B, Aegean Sea (deep water), MNHN-DJV-127; C, D, Cave no. 3, pit in cove Kravljačica, Island Kornat, ZPAL Pf.21/B670; E, F, Cap Morgiou cave, MNHN-JV (No. 20); G, H, Jarre III cave, MNHN-DJV-128. 


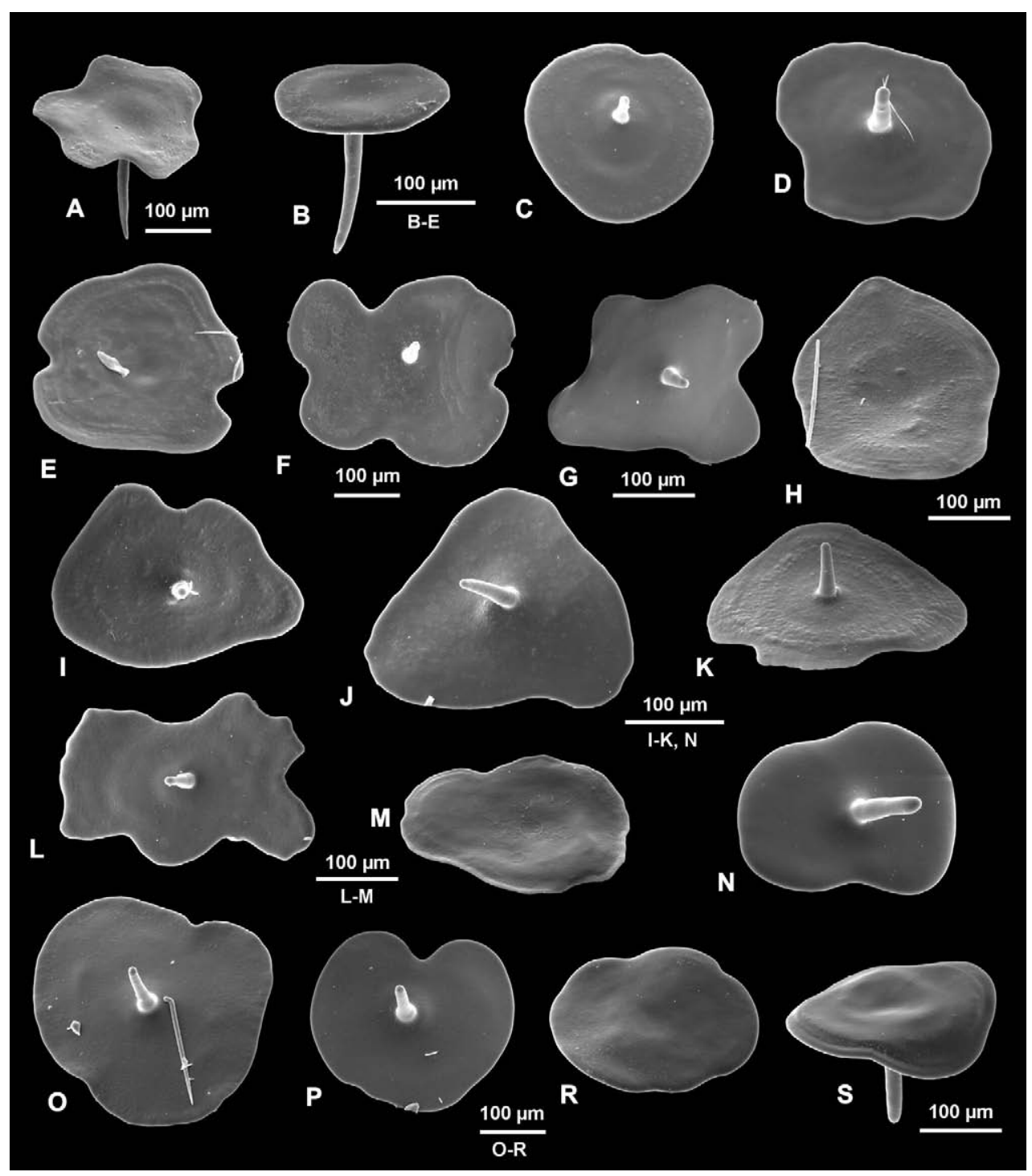

FIG. 21. - Discodermia polymorpha $\mathrm{n}$. sp., ectosomal discotriaenes in different views. A, B, F, Cave no. 3, pit cave in cove Kravljačica, Kornat Island (specimen B670); C-E, Cave no. 4, Y cave, Brbinjšćica cove, Dugi Otok, ZPAL Pf.21/B567; G, Unknown cave from the Dalmatian coast; H-K, Trémies cave, ZPAL Pf.21/7; L-M, Medes cave, MNHN-JV (No. 19); N, Jarre III cave, MNHN-DJV-128; O-S. 3PP cave, ZPAL Pf.21/6.

Occurrence and ecology. Very common in numerous caves from the western Mediterranean and the Adriatic (Medes Islands, Marseille area, Croatia), from 3 to $c a .20 \mathrm{~m}$ in dark zones, also recorded from the bathyal zone (210-360 m) in the Aegean Sea. In some caves, its abundance has been estimated to be 10 individuals $/ \mathrm{m}^{2}$ on walls or ceilings at $3 \mathrm{~m}$ depth (Pouliquen, 1972).

\section{Affinities of the studied lithistid sponges}

Because of the Messinian Event, most of the Recent fauna of the Mediterranean must be either immigrants from the Atlantic, relicts from the Pre-Messinian time (see Rögl and Steininger, 1984; Por, 1989, for a review), or recent endemics evolved in the Mediterranean Sea since the establishment of normal marine condi- tions in the Pliocene. In the case of studied lithistids we have in our material examples of the Atlantic species (Neophrissospongia nolitangere, Neoschrammeniella bowerbanki), and of new endemic species (Neophrissospongia radjae, Neophrissospongia endoumensis, Discodermia polymorpha) related to well-known Atlantic species.

This is the first record in the Mediterranean of $N$. nolitangere, a species that is known from the eastern Atlantic (including the Azores) (Lendenfeld, 1903; Topsent, 1904). The other corallistid reported in this paper, Neoschrammeniella bowerbanki, is recorded for the first time from the Mediterranean, but in fact it was earlier described in that sea by various authors under the name Corallistes masoni (see Pouliquen, 1969a, b, 1972; Magnino et al., 1999). The dead specimen studied by Magnino et al. (1999) has no microscleres 
TABLE 2. - Spicule size $(\mu \mathrm{m})$ of Discodermia polymorpha $\mathrm{n}$. sp. specimens from various caves and from single caves.

\begin{tabular}{llccc}
\hline Location/specimen & Discotriaenes & Desmas & Microrhabds & Microxeas \\
\hline Croatia & $185-215$ & $362-606$ & $15.0-21.0 \times 2.4-4.25$ & $53.8-68.3 \times 2.41(3.57)$ \\
& $180-202-234(308)$ & $450-543$ & $18.7-29.6 \times 2.85-3.38$ & $62.2-65.5 \times 2.41-2.99$ \\
& $220-324$ & $420-644$ & $17.1-29.9 \times 2.51-3.28$ & $49.6-65-8 \times 2.16-2.99$ \\
Tremies & $188-330$ (rhabdome 65) & $393-440$ & $13.2-18.1 \times 2.09-3.44$ & $32.6-48.5 \times 2.1-2.7$ \\
& $241-338$ & $471-677$ & $14.9-21.9 \times 2.55-3.55$ & $48.0-52.0 \times 2.8-3.24$ \\
Medes & $174-257$ & $409-560$ & $23.4-35 \times 2.27-3.81$ & $49.2-53.6 \times 2.12-2.8$ \\
J & $205-309 \mu \mathrm{m}$ & $563-682$ & $15.5-32.2 \times 2.24-2.93$ & $34.8-41 \times 2.28-2.83$ \\
arre III & $216-289$ & $425-595$ & $19.6-37.2 \times 1.85-2.93$ & $24.8-46.1 \times 1.66-2.32$ \\
3PP Morgiou & $243-366$ (rhabdome 60) & $498-615$ & $16.2-23.0 \times 2.47-3.24$ & $43.8-49.7 \times 2.94-3.09$ \\
& $220-338$ & $546-708$ & $14.5-17.7 \times 3.32-3.85(5.02)$ & $50.1-54.8 \times 2.62-3.78$ \\
& $241-309(398)$ & $428-668$ & $17.8-21.4(39.7) \times 2.39-3.09(3.24)$ & $47.4-55.9 \times 2.7-3.4$ \\
& $244-353$ & $430-575$ & $16.3-17.9 \times 2.08-2.85$ & $39.1-54.7 \times 2.06-2.55$ \\
& $278-360$ & $494-687$ & $17.2-22.7 \times 2.55-3.36$ & $50.5-55.7 \times 2.32-3.18$ \\
& & & & $24.5-30.3 \times 2.51-2.99$ \\
Aegean Sea (deep) & $250-318$ & $467-662$ & $13.7-18.4-26.8(43.9) \times 2.41-2.89 ;$ & $45.3-54.2 \times 2.47-3.09$ \\
\hline
\end{tabular}
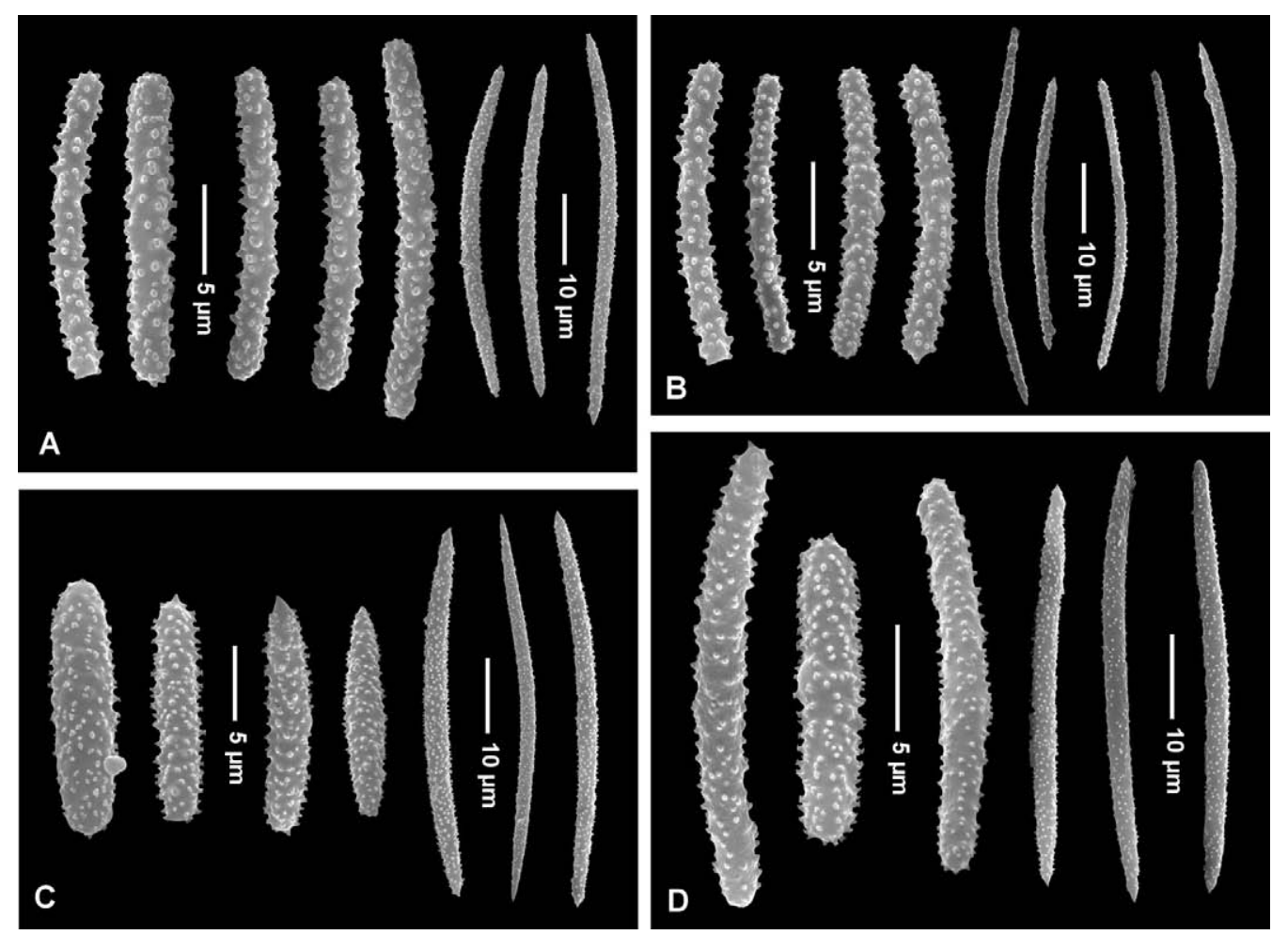

FIG. 22. - Discodermia polymorpha n. sp., microscleres (acanthorhabds and acanthoxeas) from different caves, showing the variability of these spicules. A, 3PP cave ZPAL Pf. 21/4; B, 3PP cave specimen ZPAL Pf. 21/4; C, 3PP cave MNHN-JV (specimen no.14); D. Trémies cave, ZPAL Pf.21/7.

preserved but the ectosomal dichotriaenes preserved in a few places, the characters of desmas, and a very thick wall suggest that in fact it is also $N$. bowerbanki. Thus, both $N$. bowerbanki and $N$. nolitangere are clearly immigrants from the Atlantic region. Both Neophrissospongia radjae and $N$. endoumensis are known so far only from one cave and are considered here as endemic species, closely related to but different from $N$. nolitangere. The new species Discodermia polymorpha most probably evolved in the Mediterranean but it is close to the Atlantic species $D$. polydiscus and especially $D$. ramifera, from which it probably derived.

\section{Fossilized lithistids}

In addition to the living material, several specimens of fossilized lithistid sponges were collected from the 3PP cave (deposited as MNHN-DJV-126 un- 

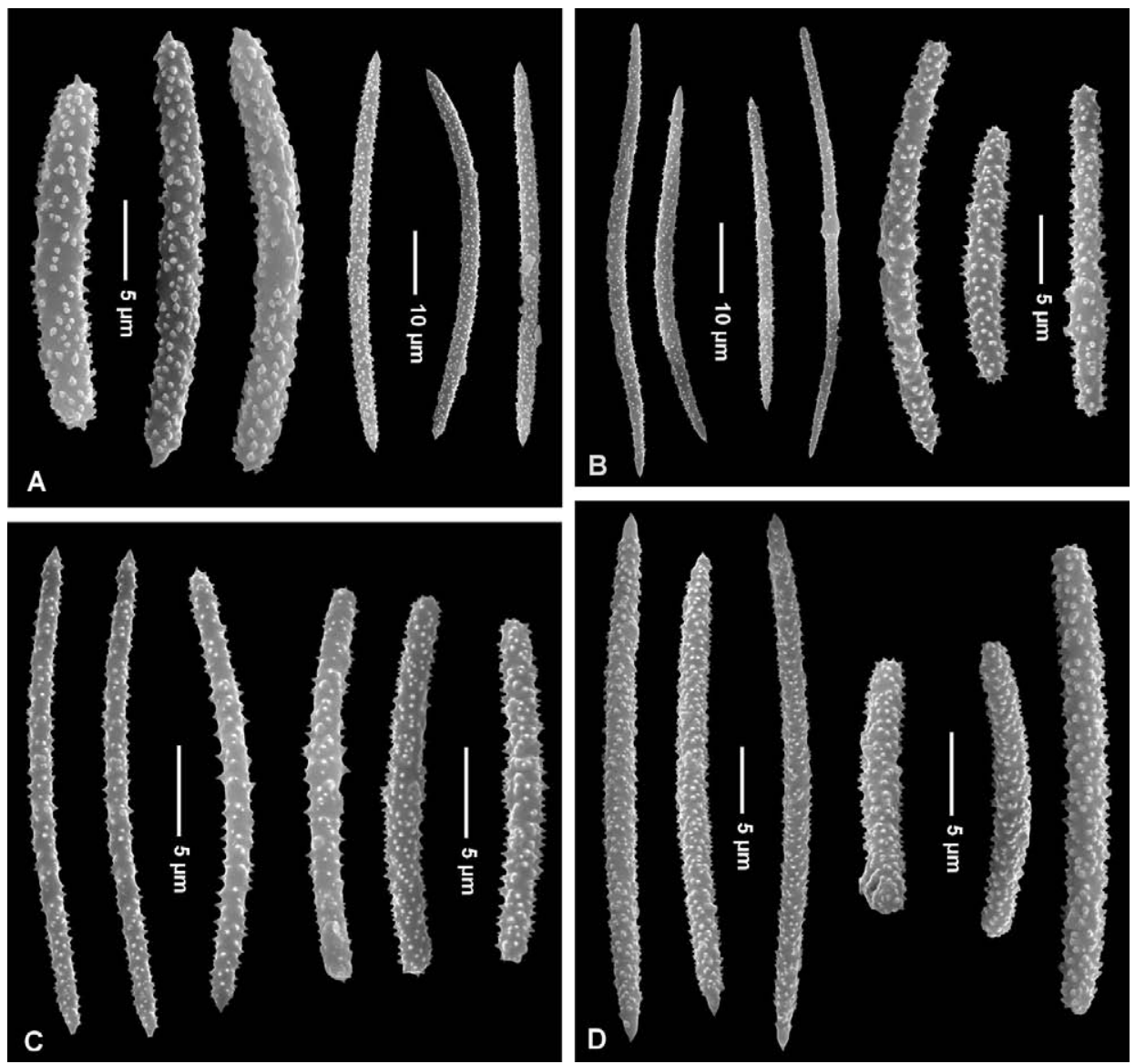

FIG. 23. - Discodermia polymorpha n. sp., microscleres (acanthorhabds and acanthoxeas) from various caves, showing the variability of spicules. A, Aegean Sea, MNHN-DJV-127; B, Cave no. 3, pit cave in cove Kravljačica, Kornat Island, ZPAL Pf.21/B670; C, Cap Morgiou cave; D, Jarre III cave, MNHN-DJV-128.

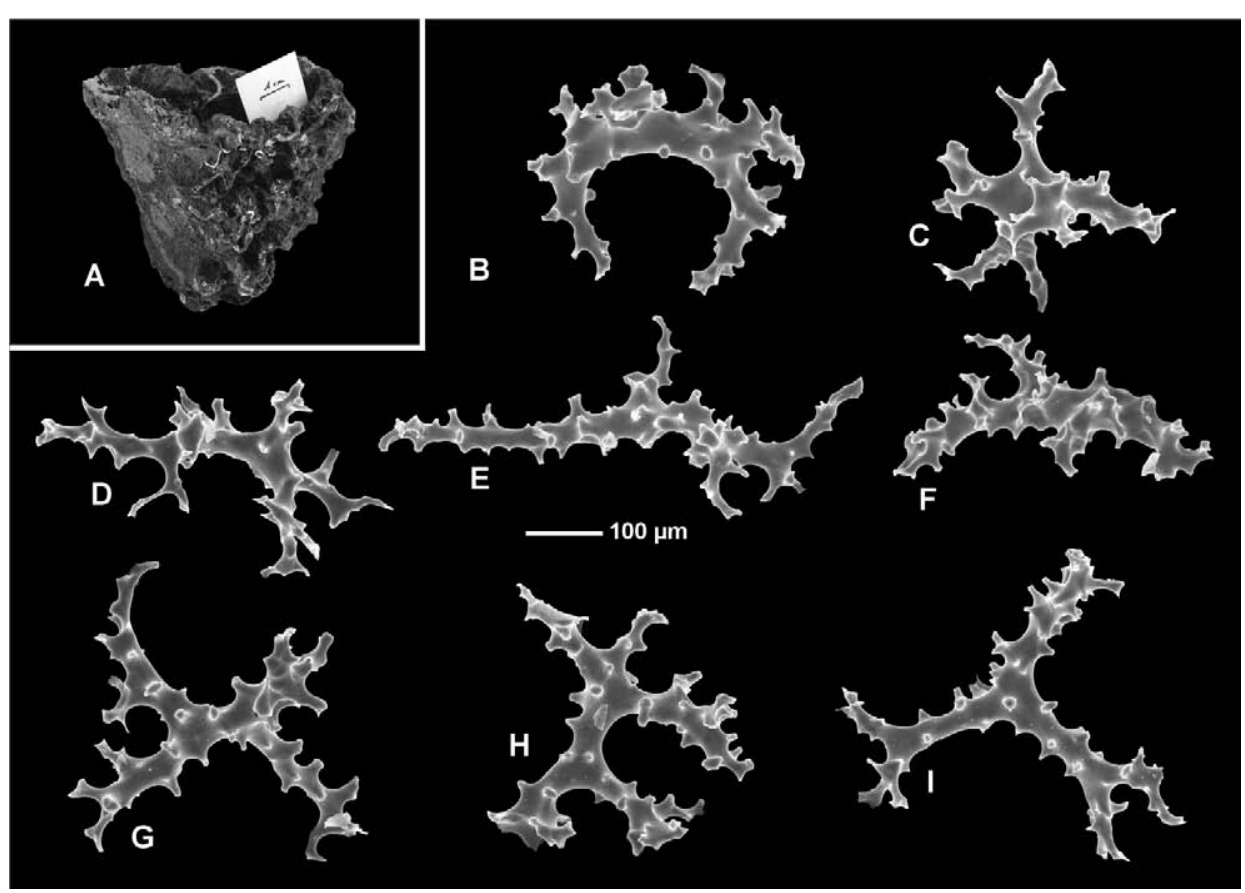

FIG. 24. - Fossilized lithistid (most probably Neoschrammeniella bowerbanki) from the 3PP cave, MNHN-DJV-126. A, Morphology of the sponge; B-I, Corroded siliceous desmas resembling rhizoclones from the fossilized sponge. 
der the name Neoschrammeniella cf. bowerbank, Fig. $24)$. They are usually conical, cup-shaped sponges and are up to $7 \mathrm{~cm}$ high and $8 \mathrm{~cm}$ in diameter at the top, with a wall up to $15 \mathrm{~mm}$ thick. The sponge body is substituted with calcium carbonate in the form of pelloids and has numerous desmas preserved. In the fossil record such types of sponge preservation by calcium carbonate are very common and they are often called "mummies" (Matyja, 1978; Pisera, 1997). Similar fossilized sponges occur in some Sardinian caves (personal observation) and in the deep Mediterranean Sea (Allouc, 1987). In the latter case they were interpreted by Allouc (1987) as relicts originating during Pleistocene cooling. In our case they are probably more recent and dating from the previous immersion of the 3PP cave dating approximately $8000 \mathrm{y}$, or from a warm episode during interglacial periods. Dating needs further verification by isotopic methods and is beyond the scope of the present paper. The problem is even more interesting because we are aware of the occurrence of similarly preserved lithistid forms in submarine caves from Sardinia.

We isolated the desmas from these fossilized lithistids by dissolving a fragment of the sponge in acetic acid (Fig. 24). At first sight the desmas resemble rhizoclones but they are larger and in some case are ornate with tubercles rather than spines, which is typical for rhizoclones. They also have an internal core of cloudy silica, which is typical for dicranoclone desmas rather than rhizoclones, and display traces of surface corrosion. Accepting their rhizoclone nature suggests that there could have been another lithistid, a rhizomorine resembling Leiodermatium, inhabiting the cave in some past. This cannot be rejected as the genus Leiodermatium was reported from the Mediterranean (Magnino et al., 1999). However, the desmas from the fossilized lithistids could also be corroded dicranoclones (during calcium carbonate deposition in the process of "mummification" $\mathrm{pH}$ values must be rather high, thus allowing for rapid corrosion of opaline spicules). If they are corroded dicranoclones, they may belong to one of the corallistids still living in the cave. In order to identify more clearly their nature, we have treated desmas of living Neoschrammeniella bowerbanki, which have similar morphology, with diluted HF acid for 5, 15 and 30 minutes. The corallistid desmas treated for 30 minutes produced corroded spicules identical to those obtained from fossilized sponges. It thus appears that the fossilized lithistids from the 3PP cave are not rhizomorine lithistids, but belong rather to one of the Corallistidae species still extant in the cave, most probably $N$. bowerbanki judging from shape, size, wall thickness and desmas general shape and size. The age and mechanisms of origin of these fossilized cave lithistids in the Mediterranean should be studied in more detail in the future, especially as they may provide interesting insights on the fossilization processes of lithistid sponges.

\section{ACKNOWLEDGEMENTS}

We are indebted to Tonci Radja (Speleološko društvo "ŠPILJAR") for supplying the specimen of a new lithistid from Croatia, to Dr. Tatjana BakranPetricioli (University of Zagreb) for supplying most of the Discodermia specimens from Dalmatian caves (obtained through collaboration within the project of the Ministry of Science and Technology of the Republic of Croatia No. 119 1226), to Dr. Joana Xavier (IBED, University of Amsterdam), to Dr. Filipe Porteiro (DOP, University of Azores) for a material and information of $N$. nolitangere for comparisons, and to Pierre Chevaldonné for supplying specimens of Discodermia and genetic information on this sponge. Warm thanks are expressed to two anonymous reviewers who helped to improve the text. This study has been possible thanks to financial support from SYNTHESYS grants FRTAF-1391 and DE-TAF-4083 to A.P., allowing the visit to MNHN Paris and NHM Berlin.

\section{REFERENCES}

Allouc, J. - 1987. Les paléocommunautés profondes sur les fonds rocheux du Pleistocène Méditerrannéen. Description et essai d'interprétation paléoécologiques. Geobios, 20: 241-263.

Bakran-Petricioli, T., and P. Kružić. - 2002. Marine caves. In: S. Gottstein Matocec (ed.), An overview of the cave and interstitial biota of Croatia. Natur. Croat., 11(suppl. 1): 77-79.

Bocage, J.V. Barboza du. - 1870. Éponges siliceuses nouvelles du Portugal et de l'île Saint-Iago (archipel de Cap-Vert). J. Sci. Mat. Phys. Nat., 4 (1869): 156-162.

Bowerbank, J.S. - 1869. A Monograph of the siliceo-fibrous sponges. Part I. Proc. Zool. Soc. Lond., 1869: 66-100.

Carter, H.J. - 1873. On the Hexactinellida and Lithistidae generally, and particularly on the Aphrocallistidae, Aulodictyon, and Farreae, together with facts elicited from their deciduous structures, and descriptions respectively of three new species. Ann. Mag. Nat. Hist., 12: 437-472.

Chombard, C. - 1998. Les Demospongiae à asters: phylogénie moléculaire et homologie morphologique. Ph.D. thesis, Mus. nat. Hist. natur., Paris.

Chombard, C., N. Boury-Esnault and S. Tillier. - 1998. Reassessment of homological characters in tetractinellid sponges based on molecular data. Syst. Biol., 47: 351-366.

Kelly, M. - 2007. The marine fauna of New Zealand: Porifera 'Lithistid' Demospongiae (rock sponges). NIWA Biodiv. Mem., 120: 1-100.

Lendenfeld, R. von. - 1903. Tetraxonia. Das Tierreich, 19: 1-168.

Lévi, C. and P. Lévi. - 1988. Nouveaux spongiaires lithistides bathyaux à affinités crétacées de la Nouvelle-Calédonie. Bull. Mus. nat. Hist. nat., Nouv. Ser. A, 10(2): 241-263.

Magnino, G., M.F. Gravina, P. Righini, F. Serena and M. Pansini. 1999. Due demosponge Lithistidi nuove per i mari italiani. Biol. Mar. Mediterr., 6(1): 391-393.

Manconi, R. and A. Serusi. - 2008. Rare sponges from marine caves: discovery of Neophrissospongia nana nov. sp. (Demospongiae, Corallistidae) from Sardinia with an annotated checklist of Mediterranean lithistids. ZooKeys, 4: 71-87.

Manconi, R., A. Serusi and A. Pisera. - 2006. A new Mediterranean "lithistid" sponge, Aciculites mediterranea n. sp. (Porifera: demospongiae) from dark marine cave in Sardinia. J. Mar. Biol. Ass. UK, 86: 1-8.

Matyja, B.A. - 1978. Struktury wczesnodiagenetyczne w wapiennych utworach oksfordu. Przegl. Geol., 3: 156-158.

Perez, T., J. Vacelet, G. Bitar and H. Zibrowius. - 2004. Two new lithistids (Porifera: Demospongiae) from a shallow Eastern Mediterranean cave (Lebanon). J. Mar. Biol. Ass. UK, 84: 15-24.

Pisera, A. - 1997. Upper Jurassic siliceous sponge from the Swa- 
bian Alb: taxonomy and paleoecology. Palaeontol. Polon., 57: $1-216$.

Pisera, A. and C. Lévi. - 2002a. Family Corallistidae Sollas. In: J.N.A. Hooper and R.W.M. Van Soest (eds.), Systema Porifera, pp. 312-320. Kluwer Academics/Plenum Publishers, New York.

Pisera, A. and C. Lévi. - 2002b. Family Theonellidae Lendenfeld. In: J.N.A. Hooper and R.W.M. Van Soest (eds.) Systema Porifera, pp. 327- 337. Kluwer Academics/Plenum Publishers, New York.

Por, F.D. - 1989. The legacy of Tethys. An aquatic biogeography of the Levant. Monogr. Biol., 63: 1-214.

Pouliquen, L. - 1969a. Les spongiaires des grottes sous-marines de la région de Marseille - écologie et systématique. $\mathrm{PhD}$ thesis, Univ. d'Aix-Marseille.

Pouliquen, L. - 1969b. Remarques sur la présence d'éponges de l'étage bathyal dans les grottes sous-marines obscures en Méditerranée. CR. Acad. Sci. Paris, 268: 1324-1326.

Pouliquen, L. - 1972. Les spongiaires des grottes sous-marines de la région de Marseille: écologie et systématique. Tethys, 3(4) (1972): 717-758.

Rögl, F. and F. Steininger. - 1984. Neogene Paratethys, Mediter- ranean and Indo-Pacific seaways. In: P. Brenchley (ed.), Fossil and Climate, pp. 171-200. Wiley, Chichester.

Schlacher, M., A. Pisera and J.N.A. Hooper. - 2005. Deep-sea "lithistid" assemblages from the Norfolk Ridge (New Caledonia), with description of seven new species and a new genus (Porifera, Demospongiae). Zoosystema, 27: 649-698.

Topsent, E. - 1892. Contribution à l'étude des Spongiaires de l'Atlantique Nord. Rés. Camp. Sci. Prince Albert I Monaco, 2: $1-165$.

Topsent, E. - 1904. Spongiaires des Açores. Rés. Camp. Sci. Prince Albert I Monaco, 25: 1-280.

Vacelet, J. - 1969. Éponges de la roche du large et de l'étage bathyal de Méditerranée. Mem. Mus. nat. Hist. nat., Nouv. Sér. A, 59: 145-219.

Zabala, M., T. Riera, J. M. Gili., M. Barange, A. Lobo and J. Peñuelas. - 1989. Water flow, trophic depletion, and benthic macrofauna impoverishment in a submarine cave from the western Mediterranean. Mar. Ecol., 10: 271-287.

Scient. ed.: M.J. Uriz.

Received October 28, 2009. Accepted April 27, 2010.

Published online November 4, 2010. 